\title{
Formation and Corrosion of a 410 SS/Ceramic Composite
}

\author{
X. Chen ${ }^{1,2}$, W.L. Ebert ${ }^{2}$, and J.E. Indacochea ${ }^{1}$ \\ ${ }^{1}$ Civil and Materials Engineering Department, University of Illinois at Chicago, 842 W. Taylor St., Chicago, IL \\ 60607 \\ ${ }^{2}$ Nuclear Engineering Division, Argonne National Laboratory, 9700 S Cass Ave, Lemont, IL 60439
}

\begin{abstract}
This study addressed the possible use of alloy/ceramic composite waste forms to immobilize metallic and oxide waste streams generated during the electrochemical reprocessing of spent reactor fuel using a single waste form. A representative composite material was made to evaluate the microstructure and corrosion behavior at alloy/ceramic interfaces by reacting 410 stainless steel with $\mathrm{Zr}$, Mo, and a mixture of lanthanide oxides. Essentially all of the available $\mathrm{Zr}$ reacted with lanthanide oxides to generate lanthanide zirconates, which combined with the unreacted lanthanide oxides to form a porous ceramic network that filled with alloy to produce a composite puck. Alloy present in excess of the pore volume of the ceramic generated a metal bead on top of the puck. The alloys in the composite and forming the bead were both mixtures of martensite grains and ferrite grains bearing carbide precipitates; FeCrMo intermetallic phases also precipitated at ferrite grain boundaries within the composite puck. Micrometer-thick regions of ferrite surrounding the carbides were sensitized and corroded preferentially in electrochemical tests. The lanthanide oxides dissolved chemically, but the lanthanide zirconates did not dissolve and are suitable host phases. The presence of oxide phases did not affect corrosion of the neighboring alloy phases.
\end{abstract}




\section{Introduction}

High-level radioactive wastes generated during the electrometallurgical reprocessing of nuclear fuel to recycle $U$ and transuranic elements will be immobilized in durable waste forms to facilitate handling, storage, transport, and final disposal in a geological repository [1,2]. The two principal high-level radioactive waste streams are salt waste contaminated with oxidized fission products and metallic waste comprised of activated cladding hulls and metallic fission products not oxidized under the processing conditions [3]. As an example, metallic waste streams generated by the reprocessing of used U-10Zr metallic fuel [4] are composed of approximately 71 mass \% contaminated cladding and 29 mass \% fuel waste $(23$ mass \% $\mathrm{Zr}$ and 6 mass \% fission products) on a fuel assembly basis. The predominant long-lived dose contributor in the metallic fuel waste is ${ }^{99} \mathrm{Tc}$, which will account for about 1 mass $\%$ of the overall metallic waste stream. Assembly hardware such as plenums, ducts, and end pieces removed during head-end processing operations prior to electrorefining will probably be compacted for separate disposal. The salt wastes include chlorides of alkali metal and alkaline earth fission products $(\mathrm{Cs}, \mathrm{Rb}, \mathrm{Ba}$, $\mathrm{Sr}$ ), lanthanides (Nd, Ce, La, Pr, Sm, Y, Pm), and trace amounts of actinides (U, Np, Pu, Am, $\mathrm{Cm}$ ) that are dissolved in the eutectic $\mathrm{LiCl} / \mathrm{KCl}$ mixture used in the electrorefiner. Waste salt removed from the electrorefiner may be immobilized directly or treated to remove actinides, lanthanides, and/or active metal ( $\mathrm{Cs}$ and $\mathrm{Sr}$ ) fission products for separate disposition in order to recycle the decontaminated $\mathrm{LiCl} / \mathrm{KCl}$ processing salt back to the electrorefiner [5]. Options for managing the wastes generated by optional treatment flowsheets are being evaluated based on the radionuclide contents, waste volumes, and processing limitations of the waste streams as well as equipment costs and footprints required in a processing facility. The benefits of partial and complete recycle for material recovery and waste minimization depend primarily on treatment and disposal costs. One means of lowering those waste management costs is decreasing the volumes and varieties of waste forms produced, including the ancillary costs of waste form qualification and regulatory acceptance for disposal.

Metallic waste forms are made by directly melting the cladding and metallic fuel wastes recovered from the electrorefiner with small amounts of trim metals to form a multi-phase alloy material in which radionuclides and other waste constituents are immobilized within a small number of chemically durable intermetallic and iron-based solid solution phases [6-10]. Trace amounts of oxide and nitride phases are commonly generated from impurities in the metals and 
melter atmosphere during the production of metallic waste forms and form a durable slag at the surface of the waste form. The present work addresses the deliberate generation of large amounts of durable ceramic phases to contain long-lived lanthanides (and actinides) in waste streams recovered from salt waste at the same time metallic fuel wastes are alloyed. In this way, both waste streams are immobilized within a single same composite waste form in one operation to decrease production, storage, and disposal costs.

Durable alloyed waste forms have been produced with Type 316L cladding hulls and new waste forms are being developed with HT9-like steel cladding that will be used in the advanced (closed) fuel cycles utilizing metallic fuels that are being designed in the US. Ferritic/martensitic stainless steels like HT9 are widely used as structural materials in fast reactors due to superior mechanical performance and radiation resistance [11-14]. Those steels were developed to enhance the resistance to creep and irradiation swelling by adding Mo, V, W, etc. as trim metals to a base Fe-12Cr stainless steel (AISI 410). We are evaluating the benefits of these and other additives to enhance the corrosion resistance of waste forms made from HT9 and similar cladding materials. Specific issues being addressed are (1) the effects of the higher $\mathrm{C}$ and lower Cr contents of HT9 relative to Type 316L stainless steel; (2) the beneficial effects provided by the passivating and noble metals present in the fuel wastes and trim metals added during waste form production; (3) the interactions occurring between the metallic and ceramic phases formed as the composite is generated; (4) whether preferential corrosion occurs at alloy/alloy, ceramic/alloy, or ceramic/ceramic phase boundaries; and (5) how to represent the contributions of phase boundaries to the overall corrosion of a composite waste form in a performance model.

We present in this paper the results of initial scoping work conducted using an alloy/oxide composite referred to as AOC410 that was made using 410 stainless steel and added Mo to represent HT9 cladding, $\mathrm{Zr}$ to represent metallic fuel waste, and a mixture of $\mathrm{La}_{2} \mathrm{O}_{3}$, $\mathrm{Nd}_{2} \mathrm{O}_{3}$, and $\mathrm{CeO}_{2}$ to represent lanthanide fuel wastes recovered from the salt waste stream. The 410 steel contains the same amounts of $\mathrm{Cr}$ and similar amount of $\mathrm{C}$ as HT9, but does not contain other trim elements (Mo, V, Ni, W, N, etc.). The alloy and oxide phases that were formed in AOC410 and the interfacial regions were characterized and their corrosion behaviors measured electrochemically and chemically. These results provide insights for producing AOC materials as high-level radioactive waste forms and modeling their long-term corrosion behaviors. 


\section{Experimental Approach}

The as-batched and elemental compositions of AOC410 are given in Table 1, including the concentrations of elements provided by the 410 steel. AOC410 was formulated to highlight the behavior of an oxide waste stream in a composite waste form. The relative amounts of lanthanide oxides used in AOC410 are higher than those expected in combined waste streams and the relative amount of $\mathrm{Zr}$ used in AOC410 is lower to facilitate measuring the disposition and release behaviors of the lanthanides and provide insights into the maximum amount of oxide waste that can be accommodated in a composite waste form. All reagents were added as powders without further treatment. (It was later determined that most of the $\mathrm{La}_{2} \mathrm{O}_{3}$ had converted to $\mathrm{La}(\mathrm{OH})_{3}$ during storage; see Section 3.1.2). Appropriate amounts of reagent powder of each component were hand-mixed inside a nitrogen atmosphere glove box then sealed in a bottle and mixed for an additional 30 minutes by using a tumbler. The mixed powders were transferred to a $\mathrm{Y}_{2} \mathrm{O}_{3}$ crucible and heated in a resistance furnace that was housed in the same glove box. The furnace was flushed with argon gas before and during heating to displace nitrogen from the vicinity of the crucible. The AOC410 mixture was heated for three hours at $1600{ }^{\circ} \mathrm{C}$ and then furnace-cooled to simulate the cooling of a full-size waste form.

[Table 1]

The materials separated during production into a cylinder puck of alloy/oxide composite and a metal bead that formed on top of that puck. These are referred to as the composite puck and metal bead, respectively. The ingot was cross-sectioned by using a diamond wafering blade and low-speed saw and then polished to a $0.05-\mu \mathrm{m}$ final surface finish by first using successively finer grit silicon carbide papers and then using colloidal silica for the final polish. Figure 1 shows a photograph of the cross-sectioned ingot. The microstructures and phase compositions of the metal bead and composite puck were characterized by using optical microscopy, scanning electron microscopy (SEM, Hitachi S-3000N) with energy dispersive X-ray emission spectroscopy (EDS, Thermo Scientific UltraDry), and powder X-ray diffraction (XRD, Siemens D5000). Kalling's No.2 etchant $\left(20 \mathrm{~mL} \mathrm{HCl}+20 \mathrm{~mL}\right.$ ethanol $\left.+1 \mathrm{~g} \mathrm{CuCl}_{2}\right)$ was used to prepare surfaces for metallography. Small pieces of the metal bead and composite puck parts of AOC410 were pulverized using an agate mortar and pestle to generate powder used for XRD analyses. 
[Figure 1]

Separate specimens about $1 \times 1 \times 10 \mathrm{~mm}^{3}$ were cut from regions in the metal bead and composite puck parts of the ingot and from the region surrounding the interface between the two parts; these regions are indicated by the red squares drawn on Figure 1a. Each specimen was fashioned into an electrode by first embedding it in a thermoplastic acrylic (Buehler TransOptic), attaching a lead wire to the back end of the specimen with silver epoxy, and then encapsulating the specimen plus a few centimeters of the lead wire in epoxy to form the electrode body. Each electrode was about $6 \mathrm{~cm}$ long and $6 \mathrm{~mm}$ in diameter and sized to fit into both a Gamry glass microcell and the SEM sample holder. The ends of the electrodes were ground to expose $\sim 1 \mathrm{~mm}^{2}$ specimen faces, which were then polished to a final $0.05-\mu \mathrm{m}$ finish. The faces were repolished between experiments to expose a fresh surface.

Potentiodynamic polarization (PD) scans and potentiostatic (PS) tests were performed by using a potentiostat (Princeton Applied Research VersaSTAT) with the AOC410 specimens used as working electrodes in a system with a graphite counter electrode and $\mathrm{KCl}$-saturated calomel reference electrode (SCE). Tests were conducted at room temperature in an air-saturated solution prepared as $0.01 \mathrm{M} \mathrm{NaCl}+0.1 \mathrm{mM} \mathrm{H}_{2} \mathrm{SO}_{4}+0.1 \mathrm{mM} \mathrm{Na}_{2} \mathrm{SO}_{4}$ (which we refer to as the acid brine solution) to characterize and compare the corrosion behaviors of the composite, bead, and interface materials in an aggressive environment. The microstructures of the electrode surfaces were characterized by using SEM/EDS prior to and after the electrochemical tests to determine which phases and interfaces corroded during the test.

\section{Results}

\subsection{AOC410 Microstructure}

The backscattered electron (BSE) SEM images in Figures $1 \mathrm{~b}$ and 1c show the metal bead and composite regions are both composed of several phases. The composite puck (the bottom half in Figure 1a) consists of sintered oxide ceramics embedded in a metal matrix, whereas the metal bead part (upper half) is free of oxides. Detailed characterizations of the composite puck and metal bead parts of the ingot are discussed in Sections 3.1.1 and 3.1.2, but we consider first 
how the composite and metal bead parts of the ingot formed. Figure 1d shows a region of the composite puck after it was severely corroded in an electrochemical test and most of the alloy phases near the electrode surface had dissolved. The polished surfaces of the ceramic phases at the electrode surface are evident and the underlying network structure of ceramic phases that formed when the material was processed is revealed. The size and shape of the composite puck (Figure 1a) indicate the ceramic structure was initially constrained by the cylindrical crucible, but densified and shrunk away from the crucible during production while the alloy remained molten. Based on Figures 1a and 1d, it appears that liquid metal in excess of the pore volume of the ceramic structure was excluded from the composite as the ceramic structure formed and flowed out of the composite puck to generate the overlying metal bead. The geometry imposed by the crucible was maintained by the ceramic structure as it densified. A metal bead formed on top of the composite puck in this case, but metal beads have formed on the tops and sides of other composites that were made with more metal. Therefore, what appear to be "islands" of ceramic domains distributed in a "sea" of metal matrix in the image shown in Figure 1c are actually cross-sections of the ceramic lattice structure that reveal the metal filling its pore spaces. The density of the ceramic structure and relative amounts of alloy in the composite and metal bead parts probably depend on the oxide content, processing time, and temperature.

\subsubsection{Characterization of the Metal Bead}

Figure 2 shows images of the metal bead that were obtained by using optical microscopy and SEM. The optical metallograph in Figure 2a shows the metal matrix to be composed of ferrite and martensite grains with carbonitride $(\mathrm{C} / \mathrm{N})$ precipitates present within the ferrite grains and at grain boundaries. The SEM image in Figure $2 \mathrm{~b}$ shows an array of $\mathrm{C} / \mathrm{N}$ precipitates within a ferritic grain along the grain boundary (G.B.) with the subtle contrast difference distinguishing the ferritic and martensitic regions. Representative compositions of the martensite and ferrite phases in the metal bead determined with EDS are provided in Table 2 (all EDS spectra were collected at an accelerating voltage of $20 \mathrm{kV}$ ). Values are given as mean and standard deviations for spot analyses at several locations in terms of wt $\%$ with values in atom $\%$ given in parentheses. The martensite grains have slightly higher $\mathrm{Cr}$ contents and lower Mo contents than the ferrite grains; no $\mathrm{Zr}$ was detected in either phase. 


\section{[Figure 2]}

[Table 2]

\subsubsection{Characterization of Composite Puck}

A typical region within the composite puck is shown in Figure 3. The martensite and ferrite grains with $\mathrm{C} / \mathrm{N}$ precipitates formed in the composite have compositions, distributions, and structures similar to those formed in the metal bead. An FeMoCr intermetallic phase formed in the metal matrix of the composite puck that was not detected in the metal bead; these were observed to occur either near a ceramic phase or along a ferrite/martensite grain boundary. The phase compositions measured using SEM/EDS are given in Table 2. The Cr contents measured in the FeCrMo intermetallic phases are slightly higher than the $\mathrm{Cr}$ contents measured in either the martensite or ferrite grains and ranged between 20 and $35 \mathrm{wt} \%$ at the expense of the Fe content. This range may indicate real variations in the stoichiometries of the intermetallics or may be an artifact of the analyzed volumes being larger than the intermetallic domains such that the analyzed volume includes a small amount of ferrite.

The irregular morphology evident in Figure 3 is common to the ceramic phases that were observed throughout the composite. Domains of lanthanide oxide, lanthanide zirconate, and $\mathrm{ZrN}$ are intimately and seemingly randomly mixed. Note that the alloys formed tight interfaces with both the lanthanide oxide and lanthanide zirconate phases even in the absence of a wetting agent. Low magnification backscattered electron images like that shown in Figure 1c were analyzed to estimate the area fractions of lanthanide zirconate and lanthanide oxide in the composite puck based on contrast differences by using ImageJ $₫$ software [15]. The volume fractions of phases in the composite are assumed to be equal to their area fractions measured in the cross sections. The total volume fraction of ceramic phases in the composite puck is estimated to be about 35\%, with ferrite, martensite, $\mathrm{C} / \mathrm{N}$ precipitates, and $\mathrm{FeCrMo}$ intermetallics comprising the remaining $65 \%$. The relative volumes of the constituent alloy phases in the composite puck and metal bead were not determined.

[Figure 3] 
Except for trace amounts of $\mathrm{ZrN}$, essentially all of the $\mathrm{Zr}$ reacted with the lanthanide oxides to form lanthanides zirconates. The relative amounts of $\mathrm{Zr}$, lanthanides and oxygen in the zirconate phase given as atom $\%$ in Table 2 are consistent with the stoichiometry $\operatorname{Ln}_{2} \mathrm{Zr}_{2} \mathrm{O}_{7}$ within the analytical uncertainties. The remaining ceramic phases are composed of mixed $\mathrm{La}$, $\mathrm{Nd}$, and $\mathrm{Ce}$ oxides, but are free of $\mathrm{Zr}$ and other alloying elements. The overall reactions indicate an additional source of oxygen is required to produce $\mathrm{La}$ and $\mathrm{Nd}$ zirconates:

$$
\begin{aligned}
& \mathrm{La}_{2} \mathrm{O}_{3}+2 \mathrm{Zr}+2 \mathrm{O}_{2}=\mathrm{La}_{2} \mathrm{Zr}_{2} \mathrm{O}_{7} \\
& \mathrm{Nd}_{2} \mathrm{O}_{3}+2 \mathrm{Zr}+2 \mathrm{O}_{2} \rightarrow \mathrm{Nd}_{2} \mathrm{Zr}_{2} \mathrm{O}_{7} .
\end{aligned}
$$

Some of the excess oxygen was probably provided by reduction of a portion of the $\mathrm{CeO}_{2}$ in the lanthanide oxide mixture from $\mathrm{Ce}$ (IV) to $\mathrm{Ce}$ (III), although the valences of $\mathrm{Ce}$ in the oxide and zirconate phases were not measured directly. The corresponding reaction is

$$
2 \mathrm{CeO}_{2}+2 \mathrm{Zr}+1.5 \mathrm{O}_{2} \rightarrow \mathrm{Ce}_{2} \mathrm{Zr}_{2} \mathrm{O}_{7} .
$$

The formation of zirconates did not appear to be limited by the availability of oxygen, although not all sources of oxygen have been identified, but it was limited by the availability of $\mathrm{Zr}$. More than $7.3 \mathrm{wt} \% \mathrm{Zr}$ would be required to convert all the lanthanide oxides in the mixture used to make AOC410 to $\mathrm{Ln}_{2} \mathrm{Zr}_{2} \mathrm{O}_{7}$ according to the stoichiometries in reactions 1a-1c. Only about half of the lanthanide oxide mixture was converted to lanthanide zirconates because only $3.1 \mathrm{wt} \% \mathrm{Zr}$ was available. As discussed above, a low $\mathrm{Zr}$ content was used to highlight the roles of lanthanide oxides as reactants and the actual blended waste streams are expected to have sufficient amounts of $\mathrm{Zr}$ to convert all the lanthanide oxides to zirconates.

The X-ray powder diffraction patterns of AOC410 and the lanthanide oxide mixture used to make AOC410 are shown in Figure 4 (measured using $\mathrm{Cu} \mathrm{K \alpha}$ radiation). Analysis of the lanthanide oxide mixture shows it was composed predominantly of $\mathrm{La}(\mathrm{OH})_{3}, \mathrm{Nd}_{2} \mathrm{O}_{3}$, and $\mathrm{CeO}_{2}$ with a small amount of $\mathrm{LaOOH}$. This indicates the $\mathrm{La}_{2} \mathrm{O}_{3}$ reagent had hydrated during storage, which provided some of the oxygen required to form zirconates. The peaks at $2 \Theta=27.0^{\circ}$ and $30.9^{\circ}$ in the XRD pattern measured for the AOC410 product indicates a small amount of residual 
$\mathrm{Nd}_{2} \mathrm{O}_{3}$ is present, but peaks corresponding to $\mathrm{La}(\mathrm{OH})_{3}$, and $\mathrm{CeO}_{2}$ (indicated in the lower pattern) were not detected. The broad peaks at $2 \theta=29.0^{\circ}, 33.6^{\circ}, 48.1^{\circ}, 57.2^{\circ}$, and $59.9^{\circ}$ (labeled P) correspond to a mixture of $\mathrm{La}^{-}, \mathrm{Nd}-$, and Ce-zirconates having the same pyrochlore structure. The peaks labeled $\alpha-\alpha^{\prime}$ at $44.6^{\circ}$ and $64.9^{\circ}$ are representative of ferritic and martensitic structures, the presence of which is consistent with the metallographic analyses. The amounts of $\mathrm{FeMoCr}$ intermetallics and $\mathrm{C} / \mathrm{N}$ precipitates in the composite are below the XRD detection limit of about $3 \operatorname{vol} \%$.

[Figure 4]

The phase distributions in the metal bead and composite parts are summarized in Table 3. Detailed analyses of the phases and interfaces in the metal and composite parts of the ingot are discussed in the following sections.

[Table 3]

\subsection{Cr Analysis}

As the major cause of sensitization corrosion, Cr depletion can have a significant impact on localized corrosion processes including pitting, crevice corrosion, and galvanic corrosion. Therefore, the $\mathrm{Cr}$ distribution near phase interfaces was examined in detail. The $\mathrm{Cr}$ concentration profiles were measured with EDS line profile and point analyses at several locations in the metal bead and composite puck. Thin regions of Cr-depleted ferrite were observed to surround the numerous $\mathrm{Cr}$-rich $\mathrm{C} / \mathrm{N}$ precipitates present inside the ferritic grains and along phase boundaries in both parts of the ingot, as discussed in the following sections.

\subsubsection{Cr analyses in Metal Bead}

A large $\mathrm{C} / \mathrm{N}$ precipitate inside a ferritic grain in the metal bead is shown in Figure 5a and the result of the line scan analysis conducted along the dashed arrow drawn in the image is included in Figure 5a. The intensity of the $\mathrm{Cr} \mathrm{K} \alpha$ line increases sharply when the precipitate is encountered. The horizontal blue dashed line is drawn to show the average $\mathrm{Cr} \mathrm{K} \alpha$ intensities in 
the ferrite grain measured well away from the precipitate. Composition analyses indicate the $\mathrm{Cr}$ contents of the precipitate and regions of the matrix away from the precipitate are $53.7 \mathrm{wt} \%$ and $11.5 \mathrm{wt} \%$, respectively. The two vertical black dotted lines are drawn to locate the interface between the $\mathrm{Cr}$-enriched precipitate and the ferrite matrix. The $\mathrm{Cr}$-depleted region extends about $1.7 \mu \mathrm{m}$ into the ferrite grain in this case, but the volume of the depleted regions appeared to vary affected by the size of the $\mathrm{C} / \mathrm{N}$ precipitate and the distance to other precipitates. Figure $5 \mathrm{~b}$ shows an array of $\mathrm{C} / \mathrm{N}$ precipitates that formed in a ferrite grain parallel to the grain boundary with a martensite grain. A line scan was conducted starting in the martensite grain, passing through the ferrite phase boundary, across the $\mathrm{C} / \mathrm{N}$ precipitates, and ending in the ferrite grain. The blue and brown lines show the $\mathrm{Cr} \mathrm{K} \alpha$ and $\mathrm{Fe} \mathrm{K} \alpha$ intensities from the line scan, respectively. The black arrows indicate the locations where spot analyses were conducted at 10 locations along the path of the line scan and the numbers behind the arrows give the $\mathrm{Cr}$ wt \% values from each spot analysis. The $\mathrm{Cr}$ contents are slightly higher in the martensite grain (>11.5 wt \% $\mathrm{Cr})$ than in the ferrite grain $(<11.0 \mathrm{wt} \% \mathrm{Cr}$ ), and below $9.7 \mathrm{wt} \%$ in the regions of ferrite adjacent to the $\mathrm{Cr}$ enriched precipitates. The widths of the $\mathrm{Cr}$-depleted regions around isolated large $\mathrm{C} / \mathrm{N}$ precipitates were typically $<2 \mu \mathrm{m}$ (as in Figure 6a), but exceeded $3 \mu \mathrm{m}$ when several $\mathrm{C} / \mathrm{N}$ precipitates were grouped along a grain or phase boundaries (as in Figure 5b).

\section{[Figure 5]}

\subsubsection{Cr analyses in Composite Puck}

The same methods were used to characterize the alloy compositions in the composite puck. The line scan represented by the dashed blue arrow shown in Figure 6a passes across a martensite/ferrite grain boundary, three $\mathrm{C} / \mathrm{N}$ precipitates, a lanthanide zirconate domain, and ends in a ferrite grain. As observed in the metal bead, the martensitic region has a higher $\mathrm{Cr}$ content $(\sim 11.8 \mathrm{wt} \%)$ than the ferrite region $(\sim 9.9 \mathrm{wt} \%)$ and $\mathrm{Cr}$ depletion occurs in the ferrite surrounding $\mathrm{C} / \mathrm{N}$ precipitates. The region between the two closely spaced precipitates is depleted in $\mathrm{Cr}$ to a greater extent than regions adjacent to the single carbide. In Figure 6a, the $\mathrm{Cr}$ contents in the ferrite between the $\mathrm{C} / \mathrm{N}$ precipitates located at distances of $3 \mu \mathrm{m}$ and $6.5 \mu \mathrm{m}$ along the scan path are slightly higher than in the ferrite between the two $\mathrm{C} / \mathrm{N}$ precipitates located at 6.5 $\mu \mathrm{m}$ and $8 \mu \mathrm{m}(\sim 9.8 \mathrm{wt} \%$ compared to $\sim 9.3 \mathrm{wt} \%)$, but lower than in the ferrite next to the grain 
boundary at about $2 \mu \mathrm{m}$ (which is $\sim 10.7 \mathrm{wt} \%$ ). Also, the extent of $\mathrm{Cr}$ depletion is greater in ferrite adjacent to larger precipitates (e.g., the precipitate near $6.5 \mu \mathrm{m}$ ) than in ferrite adjacent to smaller precipitates, such as the precipitate seen at $3 \mu \mathrm{m}$. Of course, the surface of the crosssectioned precipitate does not indicate the size of the precipitate and the measured thickness of the Cr-depleted region is likely not normal to the interface. Nevertheless, larger precipitates are expected to sequester $\mathrm{Cr}$ from a larger volume of the surrounding matrix than do smaller precipitates and the extent of $\mathrm{Cr}$ depletion in the neighboring region is expected to be more significant. Finally, an array of precipitates is observed adjacent to the $\mathrm{Ln}_{2} \mathrm{Zr}_{2} \mathrm{O}_{7} /$ ferrite phase boundary, which appears to be a pristine compact interface without micro-crevices or pores. The intensities of the $\mathrm{Zr} \mathrm{L} \alpha$ and $\mathrm{Nd} \operatorname{L} \alpha$ peaks increase sharply as the line scan passes into the lanthanide zirconate region beginning at about $8.5 \mu \mathrm{m}$ and the Fe peak intensity drops to near the background value. The $\mathrm{Nd}$ profile is representative of all lanthanides in the material. Note that overlap of the $\mathrm{Cr} \mathrm{K} \alpha$ and $\mathrm{Nd} \mathrm{L} \alpha$ peaks introduces artifacts in the line scans, including an apparent increase of $\mathrm{Nd}$ in the $\mathrm{Cr}$-enriched precipitates and a non-zero $\mathrm{Cr}$ content in the $\mathrm{Ln}_{2} \mathrm{Zr}_{2} \mathrm{O}_{7}$ region. Spot analyses were performed to provide compositions at specific locations and confirm there are no other alloy elements present in the $\mathrm{Ln}_{2} \mathrm{Zr}_{2} \mathrm{O}_{7}$ phase.

The line scan represented by the red arrow shown in Figure $6 \mathrm{~b}$ passes through a small $\mathrm{C} / \mathrm{N}$ precipitate and a FeCrMo intermetallic. The intensity of the $\mathrm{Cr} \mathrm{K} \alpha$ peak appears to remain unchanged as the line scan passes through the intermetallic. Spot analyses show the FeCrMo intermetallic has a slightly higher $\mathrm{Cr}$ content $(\sim 11.3 \mathrm{wt} \%)$ than the ferrite on either side of it ( 9.6 and $10.4 \mathrm{wt} \%$ ), but the ferrite adjacent to the intermetallic is not depleted in Cr relative to ferrite away from the interface.

[Figure 6]

\section{Electrochemical measurements}

The corrosion behaviors of the phases and interfaces in the metal and composite parts were measured in electrochemical tests conducted using the electrodes made from specimens cut from the metal and composite parts of the AOC410 ingot. The microstructures of the electrode surfaces were characterized before and after each corrosion test to identify which regions were 
active during the tests. SEM images of the polished surfaces of the metal bead and composite electrodes were shown previously in Figures $1 \mathrm{~b}$ and 1c, respectively. Each electrode was immersed in the acid brine solution for $1 \mathrm{~h}$ to measure the open circuit potential (OCP). This was followed by a PD scan from $-0.25 \mathrm{~V}$ (versus OCP) to $+1.6 \mathrm{~V}$ (versus SCE) to characterize the corrosion behavior of each electrode; the polarizing rate was $0.16 \mathrm{mV} / \mathrm{s}$. The PD scans of the metal bead electrode and composite electrode are shown together in Figure 7. The current densities are similar, but the composite electrode has a lower corrosion potential than the metal bead electrode $($ Ecorr $=$ about $-0.27 \mathrm{~V}$ compared to $-0.16 \mathrm{~V})$ and higher transpassive potential (about $0.55 \mathrm{~V}$ compared to $0.40 \mathrm{~V}$ ). The polarization curves are discussed in terms of the phase compositions in the following sections.

\section{[Figure 7]}

\subsection{Metal Bead Electrode}

SEM images are displayed in Figure 8 for two regions of the metal bead electrode before and after PD measurements. Figure 8a shows a region of mixed martensite and ferrite grains and Figures $8 \mathrm{~b}$ shows a ferrite/martensite phase boundary with an array of $\mathrm{C} / \mathrm{N}$ precipitates. The bright features in Figure 8a are $\mathrm{ZrN}$ inclusions that formed in $\mathrm{ACO} 410$. The $\mathrm{ZrN}$ phases did not corrode and were used as fiducial markers to help locate the same region of the electrode before and after corrosion. Figure 8 a shows that ferrite regions corroded as the electrode was polarized up to $1.6 \mathrm{~V}$, but martensitic regions did not corrode. Figure $8 \mathrm{~b}$ shows the same area that was analyzed by the line profile given in Figure $5 \mathrm{~b}$ (the image has been rotated for clarity). Comparing the line profile from Figure $5 \mathrm{~b}$ with the corroded region in Figure $8 \mathrm{~b}$ indicates that corrosion of ferrite surrounding the $\mathrm{C} / \mathrm{N}$ precipitates continued until the martensite grain was encountered, but the martensite did not corrode. We attribute the greater corrosion resistance of martensite to the higher $\mathrm{Cr}$ content. Corrosion into the ferrite continued to a distance of about 2.3 $\mu \mathrm{m}$ away from the array of $\mathrm{C} / \mathrm{N}$ precipitates during the PD scan. Comparison with Figure 5a indicates this is close to the width of the Cr-depleted ferrite region.

[Figure 8] 


\subsection{Composite Puck Electrode}

\subsubsection{Metal matrix within the composite puck}

The surface morphology of the corroded composite electrode is shown in Figure 9. High magnification SEM images of arrays of $\mathrm{C} / \mathrm{N}$ precipitates inside ferritic grains are provided in Figures 9a and 9b, where corrosion of the surrounding Cr-depleted regions has formed $\sim 1-\mu \mathrm{m}$ wide crevices surrounding those precipitates. Preferential corrosion of ferrite in the composite puck that had been sensitized by $\mathrm{C} / \mathrm{N}$ precipitates occurred during the PD scan of the composite electrode just as it had been in the metal bead electrode. The corrosion of matrix material adjacent to FeCrMo intermetallics is shown in Figures 9c and 9d: ferrite adjacent to intermetallics is seen to have corroded but the intermetallic phase did not corrode. The preferential corrosion at the interface is attributed to galvanic corrosion of the ferrite because composition analyses had shown the ferrite adjacent to the intermetallics was not depleted of $\mathrm{Cr}$ (e.g., in Figure 6). Figure 9d shows that the ferrite beside intermetallics formed at martensite/ferrite grain boundaries corroded, but the martensite did not. This demonstrates that ferrite is the least corrosion resistant when coupled with FeMoCr intermetallics and martensite. The light spots in Figures 9c and 9d are Mo-bearing particles that were deposited during the PD scan. That Mo had likely dissolved when the sensitized ferrite corroded and then precipitated as a Mo-oxide when the system was driven to higher potentials during the PD scan. The particles are too small to analyze quantitatively. Voids remaining after dissolution of the lanthanide oxide domains are also observed in Figure 9b; this is discussed further in Section 4.2.2.

[Figure 9]

\subsubsection{Ceramic Phases}

As presented in Section 3.1.2, about one-half of the lanthanide oxide mixture added to AOC410 was converted to lanthanide zirconates $\left(\mathrm{Ln}_{2} \mathrm{Zr}_{2} \mathrm{O}_{7}\right)$ when the ingot was made. Comparison of the polished and corroded surfaces shown in Figure 10 indicates the lanthanide oxide dissolved during the PD scan but the lanthanide zirconate domains did not dissolve; this was also seen in Figure 9b. To confirm that dissolution of the lanthanide oxides is a chemical rather than an electrochemical process, a polished composite puck electrode was immersed in the same acid brine solution used in the electrochemical tests at open circuit for 6 hours. Figure 10a 
shows the surface before and after immersion and indicates only the lanthanide oxide phases dissolved; the lanthanide zirconate and ferrite regions adjacent to $\mathrm{C} / \mathrm{N}$ precipitates or intermetallics did not dissolve. This indicates dissolution of the lanthanide oxides is a chemical process and is consistent with the rapid dissolution of lanthanide oxides observed in dilute mineral acids [16,17]. This shows the importance of converting lanthanide oxide wastes to more durable lanthanide zirconates in a composite waste form. Figure 10b shows the polished and corroded surfaces before and after a PD scan. The interfaces between alloy and $\mathrm{Ln}_{2} \mathrm{Zr}_{2} \mathrm{O}_{7}$ domains shown in Figure 10b were not corroded during the PD scan despite the complete dissolution of neighboring regions of lanthanide oxide. Areas of $\mathrm{Cr}$-depleted ferrite surrounding the $\mathrm{C} / \mathrm{N}$ inclusions that had precipitated at interfaces with the $\mathrm{Ln}_{2} \mathrm{Zr}_{2} \mathrm{O}_{7}$ were corroded, but there is no sign of metal corrosion at interfaces between alloy and lanthanide zirconate phases.

[Figure 10]

\subsection{Interface Electrode}

An electrode was prepared from a specimen cut from the metal bead/composite interface to evaluate approaches to model the corrosion behaviors of the constituent phases present in the metal and composite parts of the ingot. The electrodes made from specimens cut from the metal bead, composite substrate, and the interface provide different relative amounts of the metal matrix, sensitized ferrite, FeCrMo intermetallics, $\mathrm{C} / \mathrm{N}$ precipitates, and oxide phases that comprise the ingot. The interface electrode was prepared to provide similar areas of the metal bead and the composite puck parts of the ingot. The microstructure of the interface electrode is shown at two magnifications in Figure 11. As indicated in Section 3.1.2, FeCrMo intermetallics were observed on the composite side of the interface but not in the metal bead. These appear as worm-like features along ferrite/martensite and ferrite/ceramic grain boundaries. An abundance of $\mathrm{C} / \mathrm{N}$ precipitates can also be seen as black dots along the grain boundaries of the metal bead in the higher magnification image in the right side of Figure 11 (located by arrows).

[Figure 11] 
The results of PD scans of the three electrodes are shown plotted together in Figure 12a. The shapes of the PD curves and the current densities that were attained are very similar for the three electrodes, but the corrosion potential is lower (Ecorr $=-0.3 \mathrm{~V}$ compared to $-0.2 \mathrm{~V}$ ) and the transpassive potential is higher for the composite electrode than the corresponding values for either the metal or interface electrodes. The polarization behavior of the interface electrode is almost identical to that of the metal electrode, with only a small difference between about $0.4 \mathrm{~V}$ and $0.5 \mathrm{~V}$ (located by the arrow in Figure 12a). Because corrosion currents from the same phases contribute to the measured PD responses of all three electrodes to different extents, the observed differences reflect the relative areas of each phase exposed at the surface of each electrode. By assuming the contribution of each phase to the total current density for both metal and composite parts is linearly proportional to the relative area of that phase exposed at the electrode surface, a simulated PD curve for the interface electrode was composed using the weighted average of the corrosion currents measured for the metal and composite electrodes. Currents shown by the pink curve in Figure 12b were generated by using the following equation at each voltage:

$$
\mathrm{i}_{\text {interface }}=\mathrm{i}_{\text {metal }} \cdot A_{\text {metal }}+\mathrm{i}_{\text {composite }} \cdot A_{\text {composite }}
$$

where $\mathrm{i}_{\text {interface }}$ is the calculated current density for the interface electrode, $\mathrm{i}_{\text {metal }}$ and $\mathrm{i}_{\text {composite }}$ are the measured current densities obtained from the PD curves of the metal electrode and the composite electrode, respectively, and $A_{\text {metal }}$ and $A_{\text {composite }}$ are the relative areas of the metal and composite parts measured for the interface electrode. The measured PD curve (red curve in Figure 12a) and the calculated PD curve (pink curve in Figure 12b) for the interface electrode are in good agreement except the calculated corrosion current is slightly higher than measured between about $0.48 \mathrm{~V}$ and $0.55 \mathrm{~V}$. This is attributed to small changes in the relative areas of the constituent phases when the electrode surface was repolished between the area analysis and the PD scan.

[Figure 12]

Although the similarity of the simulated and experimental PD curves for the interface electrode supports using the relative areas to model corrosion behavior, the relative contributions 
of the phases comprising each part remained to be determined. That was done by holding the electrodes at a constant potential to corrode the active phase(s) to an extent that could be observed by using an SEM. The interface electrode was subjected to a PS test in the acid brine solution for 24 hours at $+0.42 \mathrm{~V}$, which is slightly higher than the passive region indicated by the PD curve for the interface electrode in Figure 12a. The corrosion current increased during the PS test indicating active corrosion. The electrode surface was after the test examined by using SEM to determine which phases were corroded. As shown in Figure 13, macroscopic voids and plentiful pits were generated in the ferrite surrounding $\mathrm{C} / \mathrm{N}$ precipitates on the metal bead side of the electrode during the PS test at $0.42 \mathrm{~V}$, especially along the grain boundaries where the $\mathrm{C} / \mathrm{N}$ precipitates had agglomerated. Corrosion of the composite side of the electrode occurred surrounding $\mathrm{C} / \mathrm{N}$ inclusion sites in ferrite grains and at intermetallic/ferrite interfaces identical to corroded regions that were shown in Figure 9. Extensive chemical dissolution of the lanthanide oxides was observed to have occurred on the composite side of the interface electrode, but the lanthanide zirconate phases appeared to be unreacted. This indicates the relative contributions of the constituent phases to the overall corrosion currents measured with the separate metal and composite electrodes are the same in the interface electrode. (Dissolution of the lanthanide oxides did not contribute to the corrosion current measured in the PS test.)

[Figure 13]

\section{Discussion}

The primary objective of this study was to characterize interactions that occur between metallic and oxide waste constituents during production and corrosion to assess the performance of a composite waste form. The reactions between a mixture of lanthanide oxides and $\mathrm{Zr}$ to generate lanthanide zirconates during production of AOC410 was an unexpected but highly significant result. It appears that all the available $\mathrm{Zr}$ reacted with the mixture of lanthanide oxides to generate mixed lanthanide zirconates, and that some of the oxygen required for the reaction was provided by $\mathrm{La}(\mathrm{OH})_{3}, \mathrm{LaOOH}$, and $\mathrm{CeO}_{2}$ in the oxide mixture. Another unidentified oxygen source was probably also available. The use of pyrochlore $\left(\mathrm{A}_{2} \mathrm{~B}_{2} \mathrm{O}_{7}\right)$-based ceramics as durable waste forms for actinide-bearing nuclear waste was proposed many years ago and representative 
materials have been synthesized by reacting lanthanide oxides with $\mathrm{ZrO}_{2}$ at a high temperature $\left(1400-1600{ }^{\circ} \mathrm{C}\right)$ for between 10 and 50 hours [18-20]. Lanthanide zirconates would provide an inert host phase that is resistant to radiation damage and chemically stable [21,22]. Since they can also accommodate actinide oxides [18,23-26], the zirconates formed in AOC materials may also be useful for immobilizing minor actinide-bearing waste streams. The present work shows these phases can be generated during the production of a composite waste form at about $1600{ }^{\circ} \mathrm{C}$ within processing times of a few hours if an oxygen source is present. Whereas the AOC410 material was formulated with a large excess of lanthanide oxides relative to $\mathrm{Zr}$ compared with anticipated waste stream compositions to facilitate tracking the oxide behavior, actual waste streams are expected to provide sufficient $\mathrm{Zr}$ to convert all lanthanide oxides to zirconates. Adding another oxygen source such as $\mathrm{MoO}_{2}$ or $\mathrm{Cr}_{2} \mathrm{O}_{3}$ during waste form processing would ensure all lanthanide oxides are converted to zirconates and increase the concentrations of passivating elements in the alloy phases. Furthermore, separations operations can likely be designed such that the chemical state of the oxide waste streams will facilitate the production of durable waste forms.

The oxide and zirconate domains sintered into a structural ceramic network during processing that limited the volume of alloy contained in the composite part of the ingot. As discussed above, essentially all of the added $\mathrm{Zr}$ reacted with lanthanide oxides to form lanthanide zirconates when the AOC410 was processed. The presence of both phases (and small amounts of $\mathrm{ZrN}$ ) in the ceramic network suggests the reactions with $\mathrm{Zr}$ occurred before the ceramic network structure was generated. The initial formation of the ceramic network consumed all of the available $\mathrm{Zr}$ such that $\mathrm{Zr}$-bearing alloy phases did not form in either the composite puck or metal bead. Composites made with excess $\mathrm{Zr}$ will likely form $\mathrm{Fe}-\mathrm{Zr}$ intermetallics in addition to zirconates.

The structure of the ingot indicates these ceramic phases established a rigid porous network that expelled the excess molten metal that produced the alloy bead formed on top of the composite puck. The ceramic did not fully densify into a single domain because it was sintered rather than melted. The absence of ceramic phases in the metal bead confirms the separation of molten metal occurred as the ceramic structure was forming.

The oxide phases appear to have provided nucleation sites for the FeCrMo intermetallics. The observation of these intermetallics in the composite puck but not in the metal bead suggests 
their formation was facilitated by the lower cooling rate of the composite part. Lanthanide zirconates and oxides have extremely low thermal conductivities [21,23], and the ceramic phases probably provided a slow-cooling environment in which the molten metal that remained inside of the ceramic pore structure solidified. Faster cooling in the metal bead was not conducive to precipitating the $\mathrm{FeCrMo}$ intermetallic, although the $\mathrm{C} / \mathrm{N}$ precipitates formed throughout the ingot. The amount of FeCrMo intermetallic formed in the puck was too small to impact the compositions of the ferrite or martensite grains significantly.

Adding small amounts of Mo to martensitic stainless steels is known to increase the ferrite contents [14]. The addition of 4.3 mass \% Mo to 410 steel to produce AOC410 is estimated by using the Schaeffler diagram [27] to increases the Cr-equivalent from 12.5 to $16.8 \%$, which makes the metal matrix more ferritic. Both the lower solubilities and higher diffusion rates of $\mathrm{C}$ and $\mathrm{N}$ in ferrite relative to martensite make ferrite the preferred host phase for the $\mathrm{C} / \mathrm{N}$ and intermetallic precipitates. The arrays of $\mathrm{Cr}$-rich precipitates observed along the ferrite sides of many grain boundaries are consistent with the grain boundaries serving as nucleation sites for phase transformations and precipitation reactions. Grain boundary regions have structures that are more open than the grain interiors and favor diffusion of interstitial atoms such as $\mathrm{C}$ and solute atoms such as $\mathrm{Cr}$.

The reaction between $\mathrm{Zr}$ and lanthanide oxides and the formation of the ceramic structure probably occurred during the 3 -h processing hold at $1600{ }^{\circ} \mathrm{C}$. Tight interfaces were formed between the alloy and oxide domains in the composite and alloy filled all voids in the ceramic structure. AOC410 was made with about 10 mass \% lanthanide oxides and 3 mass $\% \mathrm{Zr}$-almost all of which was oxidized - so about 14 mass \% of the ingot is ceramic and the balance is alloy. [A small amount of the added $\mathrm{Zr}$ reacted with nitrogen in the furnace atmosphere to create a $\mathrm{ZrN}$ film that enveloped a small fraction of the $\mathrm{Zr}$ and prevented reaction with lanthanide oxide; $\mathrm{ZrN}$ has not been detected in composites made subsequently in an argon atmosphere glove box.] If the density of the ceramic is assumed to be $90 \%$ that of the alloy and the composite represents 45 vol \% of the ingot volume, the composite is calculated to be comprised of $35 \mathrm{vol} \%$ ceramic and $65 \mathrm{vol} \%$ alloy. This is consistent with the area fractions measured for the region shown in Figure 1c. The amount of alloy in the metal bead provides enough metal to form composite material with an additional 16 mass $\%$ of ceramic phases, which means composite waste forms can be made with oxide waste streams loadings up to about 30 mass\%. While this exceeds the relative 
amount of lanthanide oxides expected in electrometallurgical processing wastes, it will be important for applying composite waste forms to immobilize other oxide waste streams as part of waste management strategies.

\section{Summary and Conclusions}

The microstructure and corrosion behavior of an alloy/oxide composite material AOC410 that was made to represent waste forms that immobilize combined metallic and oxide waste streams were evaluated to provide insights regarding the production and performance of composite waste forms. The composite was made using a mixture of 410 stainless steel and added Mo to represent HT9 cladding, Zr to represent metallic fuel waste, and lanthanide oxides to represent oxide wastes recovered from a salt waste stream generated during electrochemical reprocessing of sodium-bonded metallic fuel. Essentially all of the $\mathrm{Zr}$ reacted with the mixture of lanthanide oxides to form durable lanthanide zirconates when the mixture was heated to $1600{ }^{\circ} \mathrm{C}$ and held for three hours. The lanthanide zirconates and residual lanthanide oxides sintered to generate a porous ceramic network filled with alloy in the form of a composite puck. Alloy

present in excess of the amount required to fill the ceramic pore structure solidified as a metal bead on top of the puck. The alloys in the composite puck and in the bead were composed of mixtures of ferritic and martensitic grains and formed a continuous metallic phase. An abundance of $\mathrm{C} / \mathrm{N}$ precipitates formed in ferrite grains throughout the ingot but $\mathrm{FeCrMo}$ intermetallics only formed in the composite. It appears that the $\mathrm{C} / \mathrm{N}$ precipitates and $\mathrm{FeCrMo}$ intermetallics formed after the ceramic network had been formed. The formation of ceramic phases having low thermal conductivities probably affected the cooling rate of the metal in its pores and promoted precipitation of FeCrMo intermetallics in the composite part of the ingot. We have observed the preferential precipitation of intermetallics in the composite regions of other materials and are investigating how the cooling rates affect the growth kinetics of $\mathrm{C} / \mathrm{N}$ precipitates and intermetallics.

The formation of an oxide-free alloy bead that separated from the alloy/ceramic composite during material production allowed the electrochemical corrosion behaviors of the metal bead and composite parts of the ingot to be studied independently. The most readily corroded material in both parts was the typically 1-3 $\mu \mathrm{m}$ thick region of $\mathrm{Cr}$-depleted steel surrounding each $\mathrm{C} / \mathrm{N}$ precipitate. The thickness of $\mathrm{Cr}$-depleted regions and the extent of 
depletion appeared to depend on the size and local abundance of precipitated phases. The ferritic regions surrounding FeCrMo intermetallic phases that formed in the composite puck were not depleted in $\mathrm{Cr}$, but were preferentially corroded nonetheless due to galvanic coupling with the intermetallics.

The $\mathrm{Cr}$ and $\mathrm{C}$ contents of 410 and HT9 steels are about the same, so the effects of C/N precipitates on the corrosion of AOC410 are directly relevant to all HT9-based waste forms. Adding $\mathrm{Cr}$ as a trim metal to waste forms made with HT9-type cladding is expected to mitigate sensitization of the steel surrounding the $\mathrm{C} / \mathrm{N}$ precipitates. Providing sufficient $\mathrm{Cr}$ to maintain levels above $12 \mathrm{wt} \%$ in the ferrite at phase boundaries will benefit the overall corrosion resistance of composite and alloy-only waste forms made with HT9 cladding. Adding elements that are better carbide formers than $\mathrm{Cr}$, such as $\mathrm{V}$ and $\mathrm{Nb}$, will also decrease $\mathrm{Cr}$ depletion in the matrix.

The lanthanide oxides used to make AOC410 mimic the lanthanide oxide wastes that will accumulate during the electrorefining process and be stored prior to waste form production. A benefit of immobilizing lanthanide oxide wastes in an alloyed waste form is that they will react with $\mathrm{Zr}$ from the fuel waste to form highly durable lanthanide zirconates if sufficient oxygen is available. Zirconium plays an important role in metallic waste forms, as actinides are known to be incorporated in Fe-Zr intermetallics in alloy-only waste forms $[8,10]$. Since $\mathrm{CeO}_{2}$ is often used as a surrogate for $\mathrm{PuO}_{2}$, the incorporation of $\mathrm{Ce}$ in zirconates formed in AOC410 suggests the ceramic phases may serve as additional hosts for actinide wastes. Waste forms providing both zirconates and Fe-Zr intermetallics to host lanthanides and actinides would provide a valuable option for waste treatment and management strategies.

\section{Acknowledgements}

The authors gratefully acknowledge funding under DOE Nuclear Energy University Program Grant DE-NE-IL-UIC-0203-02 and thank Drs. Terry Cruse and Jeffery Fortner (ANL) for assistance with the electrochemical tests and microscopy, and Tahsin Rahman (UIC) and Vineeth Gattu (UIC) for helpful discussions. They also thank an anonymous reviewer for constructive suggestions. Work conducted at Argonne National Laboratory is supported by the U.S. Department of Energy, Office of Nuclear Energy, under Contract DE-AC02-06CH11357. 


\section{References}

[1] Ackerman, J. P., Johnson, T. R., Chow, L. S. H., Carls, E. L., Hannum, W. H., and Laidler, J. J. (1997). Treatment of wastes in the IFR fuel cycle. Progress in Nuclear Energy, 31(1), 141-154.

[2] Laidler, J. J., Burris, L., Collins, E. D., Duguid, J., Henry, R. N., Hill, J., et al. (2001). Chemical partitioning technologies for an ATW system. Progress in Nuclear Energy, 38(1), $65-79$.

[3] Ebert, W. L. Testing to evaluate the suitability of waste forms developed for electrometallurgically treated spent sodium-bonded nuclear fuel for disposal in the Yucca Mountain repository. Argonne National Laboratory report ANL-05/43. ANL, 2006.

[4] Chang, Y. I. (2007). Technical rationale for metal fuel in fast reactors. Nuclear Engineering and Technology, 39(3), 161-170.

[5] Williamson, M. A., and Willit, J. L. (2011). Pyroprocessing flowsheets for recycling used nuclear fuel. Nuclear Engineering and Technology, 43(4), 329-334.

[6] McDeavitt, S. M., Abraham, D. P., and Park, J. Y. (1998). Evaluation of stainless steelzirconium alloys as high-level nuclear waste forms. Journal of Nuclear Materials, 257(1), 21-34.

[7] Abraham, D. P., McDeavitt, S. M., and Park, J. Y. (1996). Microstructure and phase identification in type 304 stainless steel-zirconium alloys. Metallurgical and Materials Transactions A, 27(8), 2151-2159.

[8] Keiser, D. D., Abraham, D. P., Sinkler, W., Richardson, J. W., and McDeavitt, S. M. (2000). Actinide distribution in a stainless steel-15 wt \% zirconium high-level nuclear waste form. Journal of Nuclear Materials, 279(2), 234-244.

[9] Chen, J., Asmussen, R. M., Zagidulin, D., Noël, J. J., and Shoesmith, D. W. (2013). Electrochemical and corrosion behavior of a 304 stainless-steel-based metal alloy wasteform in dilute aqueous environments. Corrosion Science, 66, 142-152.

[10] Janney, D. E. (2003). Host phases for actinides in simulated metallic waste forms. Journal of Nuclear Materials, 323(1), 81-92.

[11] Chen, Y. (2013). Irradiation Effects of HT-9 Martensitic Steel. Nuclear Engineering and Technology, 45(3), 311-322. 
[12] Masuyama, F. (2001). History of power plants and progress in heat resistant steels. ISIJ International, 41(6), 612-625.

[13] Klueh, R. L., and Harries, D. R. (2001). High-chromium ferritic and martensitic steels for nuclear applications (Vol. 3). ASTM International.

[14] Klueh, R. L. (2005). Elevated temperature ferritic and martensitic steels and their application to future nuclear reactors. International Materials Reviews, 50(5), 287-310.

[15] Rasband, W.S., ImageJ, U. S. National Institutes of Health, Bethesda, Maryland, USA, http://imagej.nih.gov/ij/, 1997-2016.

[16] Horlait, D., Clavier, N., Szenknect, S., Dacheux, N., \& Dubois, V. (2012). Dissolution of cerium (IV)-Lanthanide (III) oxides: comparative effect of chemical composition, temperature, and acidity. Inorganic Chemistry, 51(6), 3868-3878.

[17] Billard, I., Gaillard, C., \& Hennig, C. (2007). Dissolution of $\mathrm{UO}_{2}, \mathrm{UO}_{3}$ and of some lanthanide oxides in BumimTf $2 \mathrm{~N}$ : effect of acid and water and formation of $\mathrm{UO}_{2}\left(\mathrm{NO}_{3}\right)_{3}{ }^{-}$. Dalton Transactions, (37), 4214-4221.

[18] Ewing, R. C., Weber, W. J., and Clinard, F. W. (1995). Radiation effects in nuclear waste forms for high-level radioactive waste. Progress in Nuclear Energy, 29(2), 63-127.

[19] Kong, L., Zhang, Y., Karatchevtseva, I., Blackford, M. G., Lumpkin, G. R., and Triani, G. (2014). Synthesis and characterization of Nd 2 Sn x Zr 2- x O 7 pyrochlore ceramics. Ceramics International, 40(1), 651-657.

[20] Loiseau, P., and Caurant, D. (2010). Glass-ceramic nuclear waste forms obtained by crystallization of $\mathrm{SiO} 2-\mathrm{Al} 2 \mathrm{O} 3-\mathrm{CaO}-\mathrm{ZrO} 2-\mathrm{TiO} 2$ glasses containing lanthanides $(\mathrm{Ce}$, $\mathrm{Nd}, \mathrm{Eu}, \mathrm{Gd}, \mathrm{Yb}$ ) and actinides (Th): Study of the crystallization from the surface. Journal of Nuclear Materials, 402(1), 38-54.

[21] Lutique, S., Staicu, D., Konings, R. J. M., Rondinella, V. V., Somers, J., and Wiss, T. (2003). Zirconate pyrochlore as a transmutation target: thermal behaviour and radiation resistance against fission fragment impact. Journal of Nuclear Materials, 319, 59-64.

[22] Vance, E. R., Jostsons, A., Day, R. A., Ball, C. J., Begg, B. D., and Angel, P. J. (1995). Excess Pu disposition in zirconolite-rich synroc. In MRS Proceedings (Vol. 412, p. 41). Cambridge University Press. 
[23] Ewing, R. C., Weber, W. J., and Lian, J. (2004). Nuclear waste disposal-pyrochlore (A2B2O7): Nuclear waste form for the immobilization of plutonium and "minor" actinides. Journal of Applied Physics, 95(11), 5949-5971.

[24] Dosch, R. G., Headley, T. J., and Hlava, P. (1984). Crystalline titanate ceramic nuclear waste forms: processing and microstructure. Journal of the American Ceramic Society, 67(5), 354-361.

[25] Turcotte, R. P., Wald, J. W., Roberts, F. P., Rusin, J. M., and Lutze, W. (1982). Radiation damage in nuclear waste ceramics. Journal of the American Ceramic Society, 65(12), 589593.

[26] Ringwood, A. E., Kesson, S. E., Ware, N. G., Hibberson, W., and Major, A. (1979). Immobilisation of high level nuclear reactor wastes in SYNROC. Nature, 278, 219-223

[27] Schaeffler, A. L., (1949). Constitution Diagram for Stainless-steel Weld Metal. 2. Schaeffler Diagram. Metal Progress, 56, 680-680B. 
Table 1. As-batched elemental composition of AOC410, in wt \%

\begin{tabular}{cccccccccccccc}
\hline \multicolumn{10}{c}{$410 \mathrm{SS}}$. \\
\cline { 1 - 3 } & $\mathrm{Cr}$ & $\mathrm{Mn}$ & $\mathrm{Si}$ & $\mathrm{C}$ & $\mathrm{P}$ & $\mathrm{S}$ & $\mathrm{Zr}$ & $\mathrm{Mo}$ & $\mathrm{La}_{2} \mathrm{O}_{3}$ & $\mathrm{Nd}_{2} \mathrm{O}_{3}$ & $\mathrm{CeO}_{2}$ \\
\hline Bal. & 10.2 & $<0.08$ & $<0.08$ & $<0.12$ & $<0.03$ & $<0.02$ & 3.1 & 4.3 & 1.5 & 5.0 & 3.5 \\
\hline
\end{tabular}


Table 2. Representative compositions of constituent phases ${ }^{a}$

\begin{tabular}{ccccccccc}
\hline & $\mathrm{Fe}$ & $\mathrm{Cr}$ & $\mathrm{Mo}$ & $\mathrm{Zr}$ & $\mathrm{La}$ & $\mathrm{Ce}$ & $\mathrm{Nd}$ & $\mathrm{O}$ \\
\hline \multirow{7}{*}{ Martensite } & $83.8 \pm 0.2$ & $12.0 \pm 0.1$ & $4.2 \pm 0.2$ & - & - & - & - & - \\
& $(84.5 \pm 0.1)$ & $(13.0 \pm 0.1)$ & $(2.5 \pm 0.1)$ & & & & \\
\hline \multirow{2}{*}{ Ferrite } & $83.9 \pm 0.9$ & $11.2 \pm 0.6$ & $4.9 \pm 0.7$ & - & - & - & - \\
& $(84.9 \pm 0.7)$ & $(12.2 \pm 0.6)$ & $(2.9 \pm 0.4)$ & & & & - \\
\hline
\end{tabular}

Composite Puck

\begin{tabular}{|c|c|c|c|c|c|c|c|c|}
\hline Martensite & $\begin{array}{c}83.9 \pm 0.3 \\
(84.6 \pm 0.2)\end{array}$ & $\begin{array}{c}12.0 \pm 0.1 \\
(13.0 \pm 0.1)\end{array}$ & $\begin{array}{c}4.1 \pm 0.2 \\
(2.4 \pm 0.1)\end{array}$ & - & - & - & - & - \\
\hline Ferrite & $\begin{array}{c}84.1 \pm 1.1 \\
(84.9 \pm 0.8)\end{array}$ & $\begin{array}{c}11.4 \pm 0.5 \\
(12.4 \pm 0.5)\end{array}$ & $\begin{array}{c}4.5 \pm 0.8 \\
(2.7 \pm 0.5)\end{array}$ & - & - & - & - & - \\
\hline FeCrMo & $\begin{array}{c}59.5 \pm 5.2 \\
(66.6 \pm 4.3)\end{array}$ & $\begin{array}{c}12.2 \pm 0.5 \\
(14.8 \pm 0.8)\end{array}$ & $\begin{array}{c}28.3 \pm 5.0 \\
(18.5 \pm 3.7)\end{array}$ & - & - & - & - & - \\
\hline Ln Oxide & - & - & - & - & $\begin{array}{c}10.5 \pm 0.3 \\
(5.0 \pm 0.2)\end{array}$ & $\begin{array}{c}29.1 \pm 2.3 \\
(13.9 \pm 1.5)\end{array}$ & $\begin{array}{c}46.0 \pm 2.0 \\
(21.3 \pm 1.4)\end{array}$ & $\begin{array}{c}14.4 \pm 1.3 \\
(59.8 \pm 2.4)\end{array}$ \\
\hline Ln Zirconate & - & - & - & $\begin{array}{c}33.3 \pm 2.8 \\
(19.9 \pm 2.5)\end{array}$ & $\begin{array}{c}8.1 \pm 0.9 \\
(3.2 \pm 0.4)\end{array}$ & $\begin{array}{c}15.7 \pm 1.3 \\
(6.1 \pm 0.6)\end{array}$ & $\begin{array}{l}24.6 \pm 0.8 \\
(9.3 \pm 0.8)\end{array}$ & $\begin{array}{c}18.2 \pm 2.0 \\
(61.5 \pm 3.3)\end{array}$ \\
\hline
\end{tabular}

${ }^{\mathrm{a}}$ Values given in wt \%; values in parentheses are at $\%$. 
Table 3. Phase compositions of metal bead and composite puck

\begin{tabular}{ccc}
\hline Phases present & Metal bead & Composite puck \\
\hline Metal matrix & Martensite and ferrite grains & Martensite and ferrite grains \\
\hline $\mathrm{C} / \mathrm{N}$ inclusions & $\begin{array}{c}\text { Heavily agglomerated in ferrite } \\
\text { grains and at ferrite/martensite } \\
\text { grain boundaries }\end{array}$ & $\begin{array}{c}\text { Precipitated in ferrite grains and at } \\
\text { ferrite/martensite grain boundaries }\end{array}$ \\
\hline $\begin{array}{c}\mathrm{FeMoCr} \\
\text { intermetallic }\end{array}$ & Not detected & $\begin{array}{c}\text { Uniformly distributed in metal } \\
\text { matrix throughout composite. }\end{array}$ \\
\hline $\begin{array}{c}\mathrm{Ln}_{2} \mathrm{Zr}_{2} \mathrm{O}_{7} \text { and } \\
\text { lanthanide oxide }\end{array}$ & Not detected & $\begin{array}{c}35 \text { volume percent*. Exhibit } \\
\text { sintered ceramic network. }\end{array}$ \\
\hline
\end{tabular}

* The volume fraction is assumed equal to the area fraction. 


\section{List of Figures}

Figure 1. Cross section of the as-cast sample showing (a) the metal bead and composite puck and locations from which electrodes were cut (red squares), SEM BSE images of (b) the metal bead part and (c) the composite puck, and (d) the ceramic network revealed after electrochemical dissolution of the metal phases in the composite puck.

Figure 2. Regions of the metal bead observed by (a) optical metallography, (b) SEM.

Figure 3. SEM BSE images of the composite puck.

Figure 4. Powder XRD patterns of the lanthanide oxides mixture (lower pattern) and AOC410 (upper pattern). Peaks cited in text are indicated by arrows.

Figure 5. SEM images and EDS line scans of regions in the metal bead: (a) isolated C/N precipitate in a ferrite grain and (b) an array of $\mathrm{C} / \mathrm{N}$ precipitates at a martensite/ferrite grain boundary.

Figure 6. SEM images and EDS line scans of regions in the composite puck: (a) martensite/ferrite grain boundary, $\mathrm{C} / \mathrm{N}$ precipitates, and zirconate inclusion in ferrite, and (b) $\mathrm{C} / \mathrm{N}$ precipitate and intermetallic in ferrite.

Figure 7. Potentiodynamic curves measured with the metal bead and composite electrodes.

Figure 8. SEM (BSE) images before and after PD scan showing surface morphology change at (a) low and (b) high magnification.

Figure 9 SEM images composite puck electrode after PD scan showing preferential corrosion of (a) and (b) ferrite surrounding $\mathrm{C} / \mathrm{N}$ precipitates, and (c) and (d) ferrite at intermetallic boundary.

Figure 10. SEM images of ceramic puck electrode before and after (a) chemical dissolution and (b) PD scan.

Figure 11. SEM image of interface electrode. The arrows in the right-hand image locate regions of $\mathrm{C} / \mathrm{N}$ precipitates formed at grain boundaries.

Figure 12. Measured PD curves of the metal and composite parts shown with (a) the measured PD curve of the interface electrode and (b) the calculated anodic curve of interface electrode. The arrow locates a subtle difference between the responses of the metal and interface electrodes.

Figure 13. SEM image of the corroded interface electrode. 


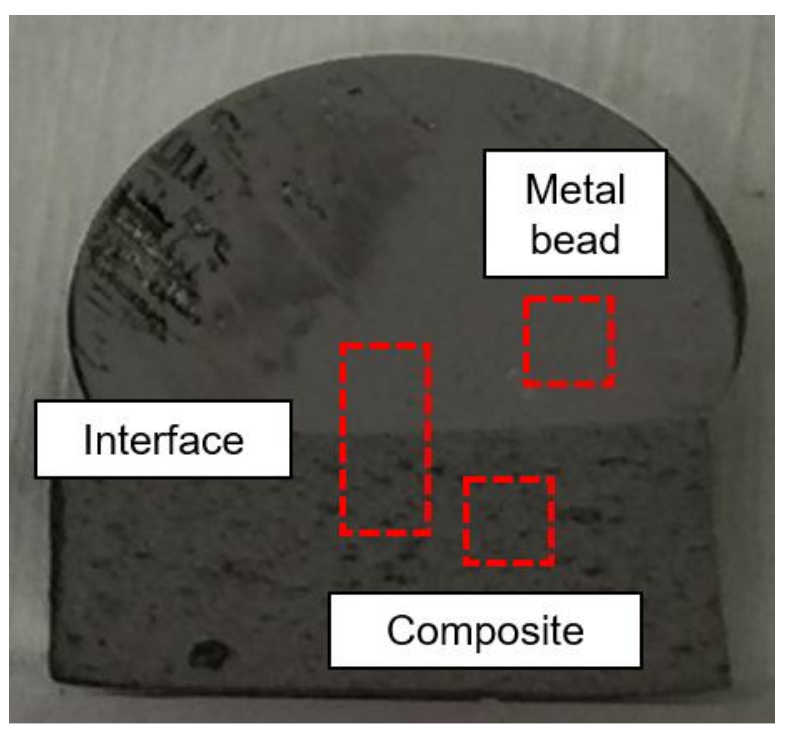

$5 \mathrm{~mm}$

(a)

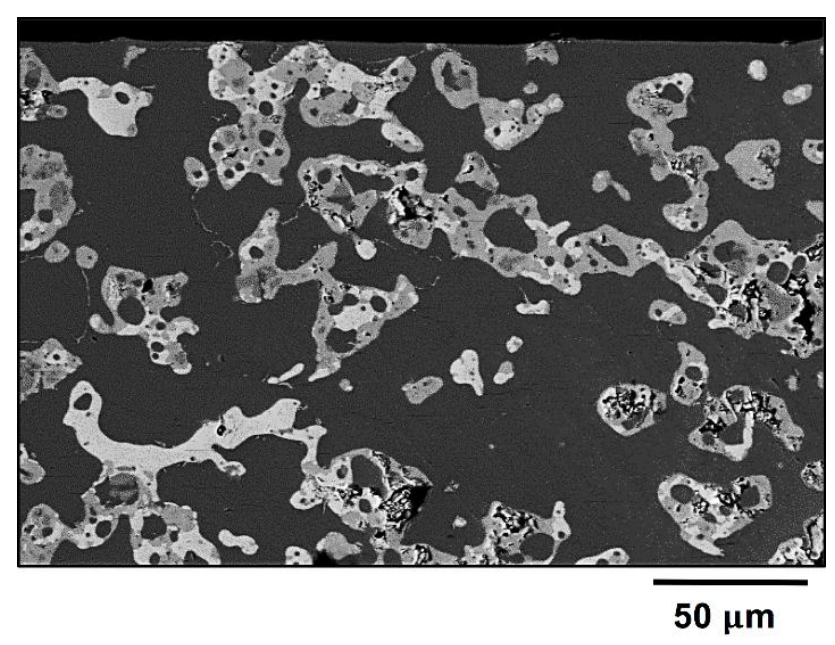

(c)

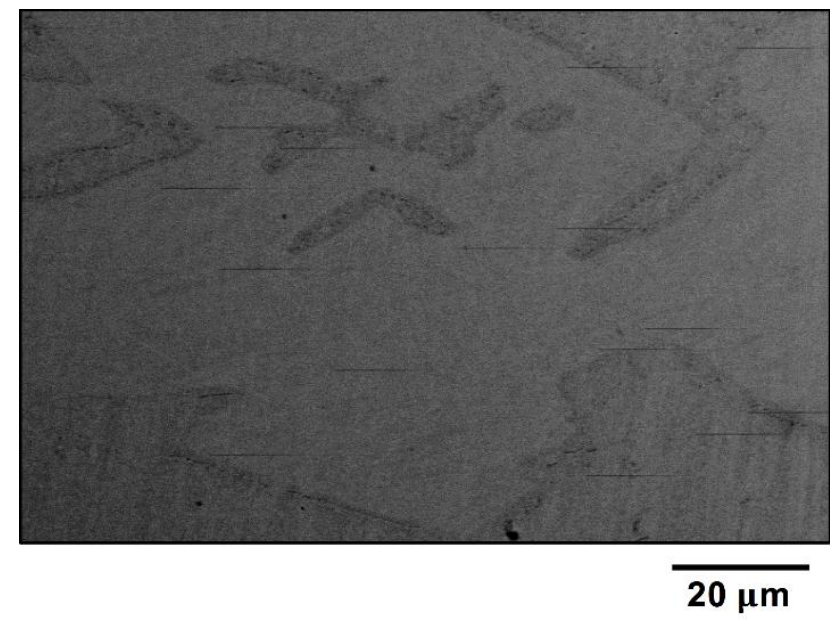

(b)

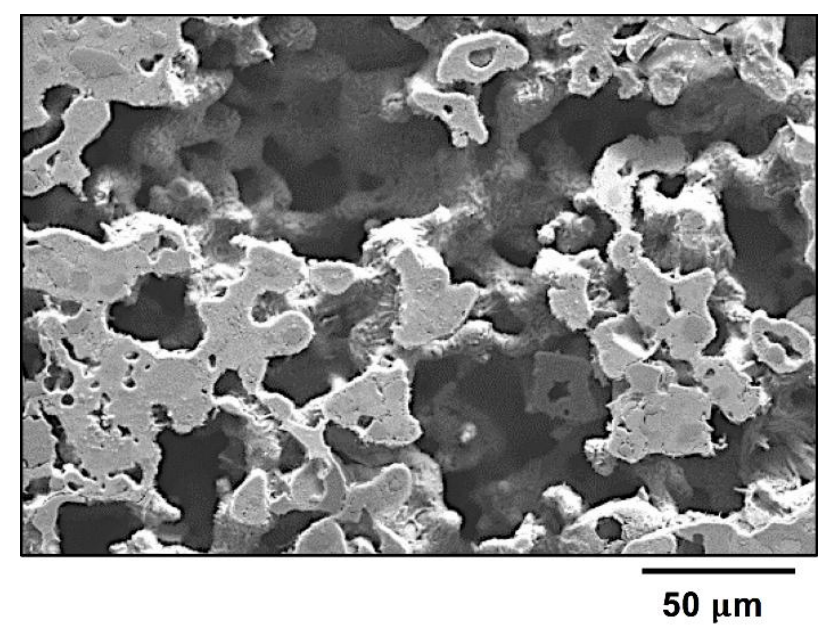

(d)

Figure 1. Cross section of the as-cast sample showing (a) the metal bead and composite puck and locations from which electrodes were cut (red squares), SEM BSE images of (b) the metal bead part and (c) the composite puck, and (d) the ceramic network revealed after electrochemical dissolution of the metal phases in the composite puck. 


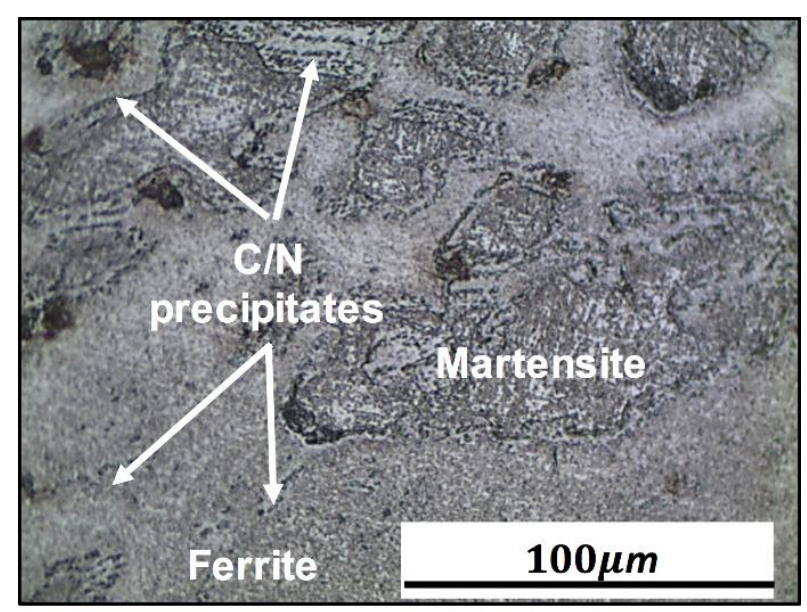

(a)

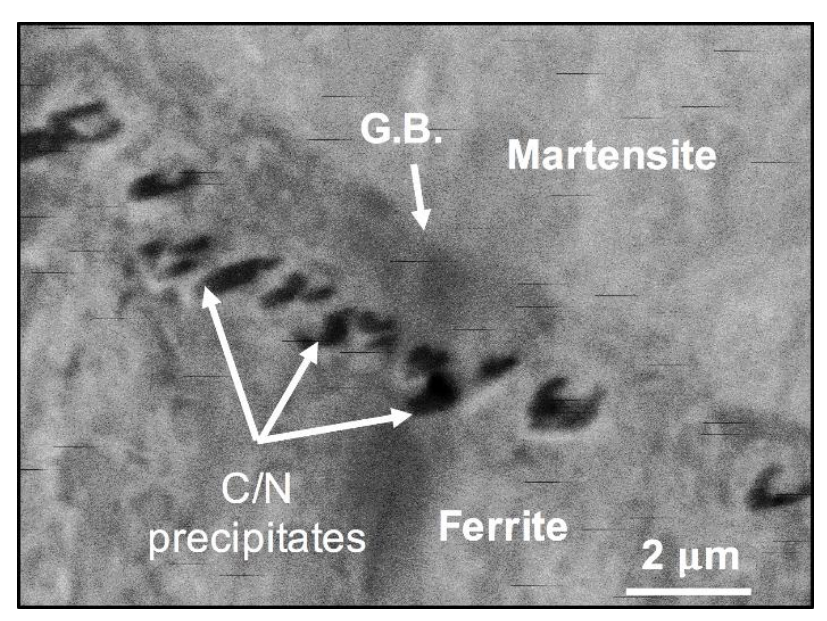

(b)

Figure 2. Regions of the metal bead observed by (a) optical metallography, (b) SEM. 


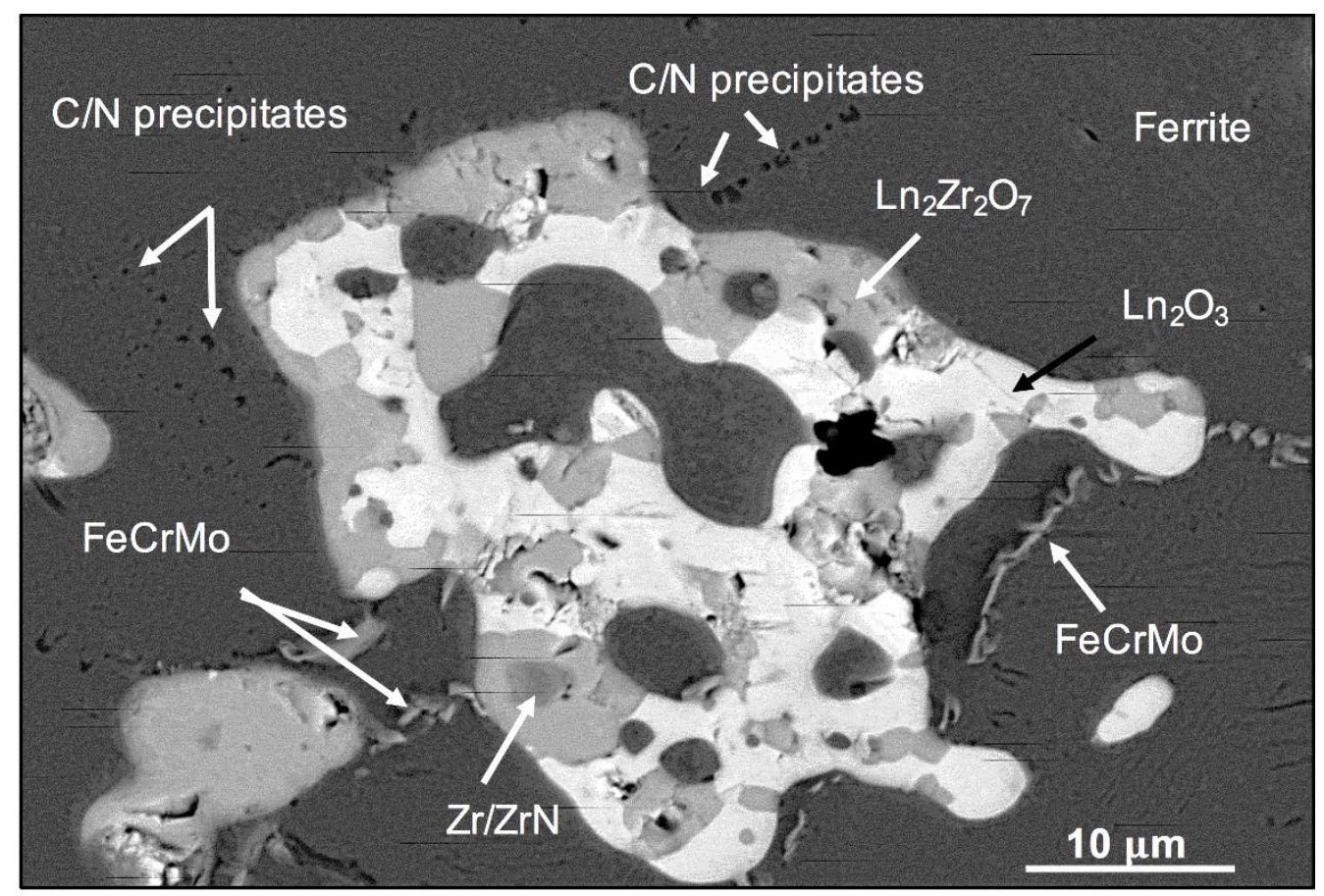

Figure 3. SEM BSE images of the composite puck. 


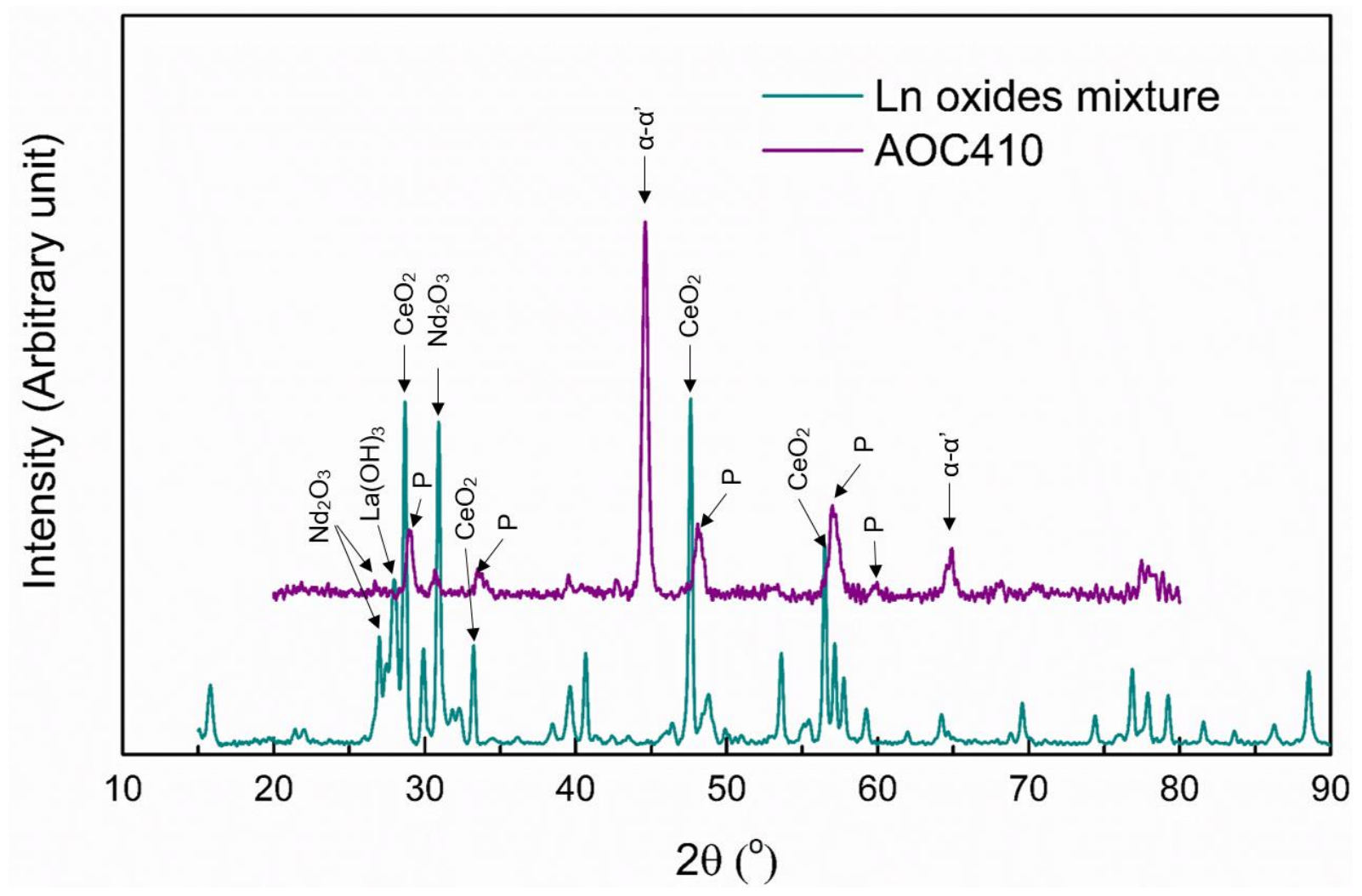

Figure 4. Powder XRD patterns of the lanthanide oxides mixture (lower pattern) and AOC410 (upper pattern). Peaks cited in text are indicated by arrows. 


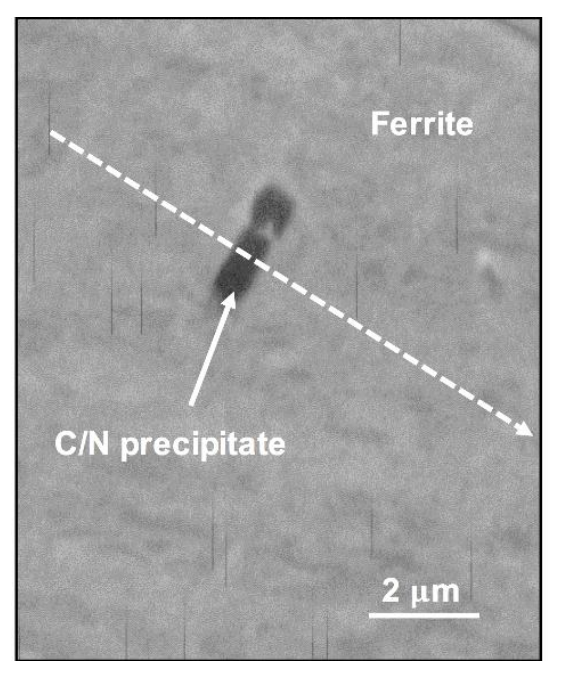

(a)

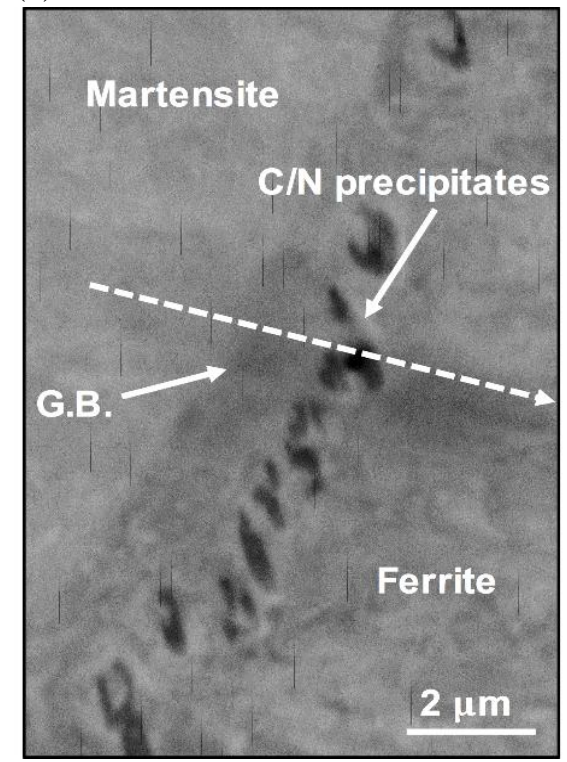

(b)
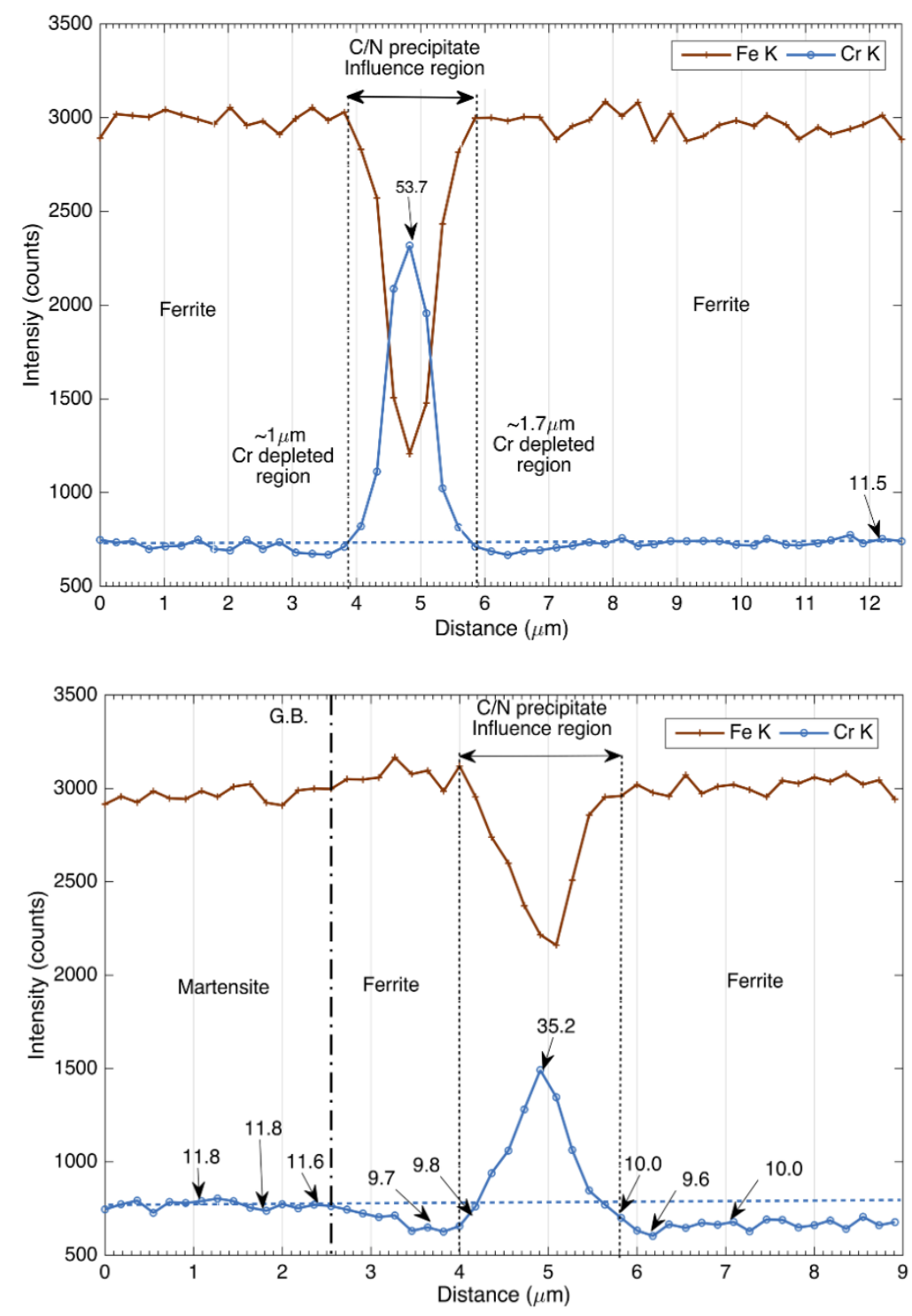

Figure 5. SEM images and EDS line scans of regions in the metal bead: (a) isolated C/N precipitate in a ferrite grain and (b) an array of $\mathrm{C} / \mathrm{N}$ precipitates at a martensite/ferrite grain boundary. 


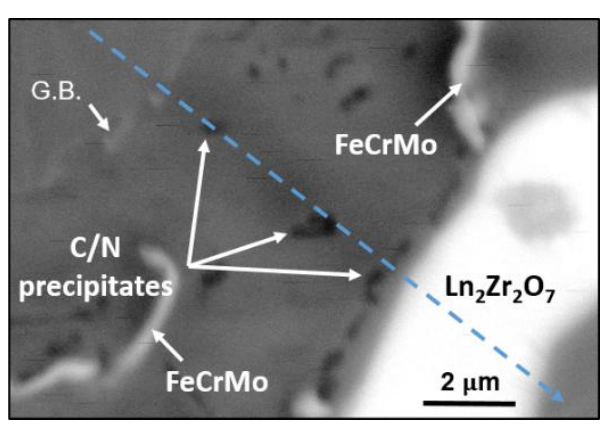

(a)

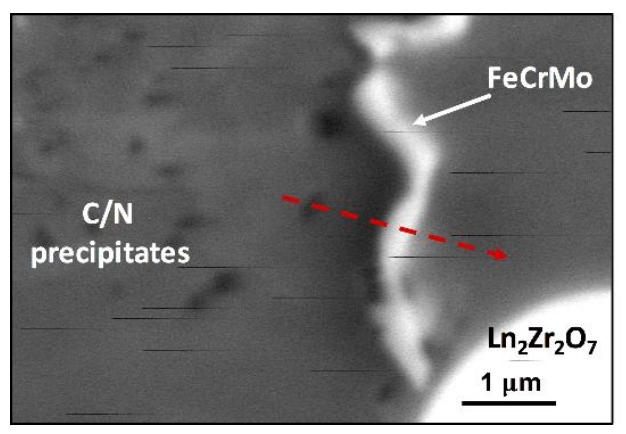

(b)
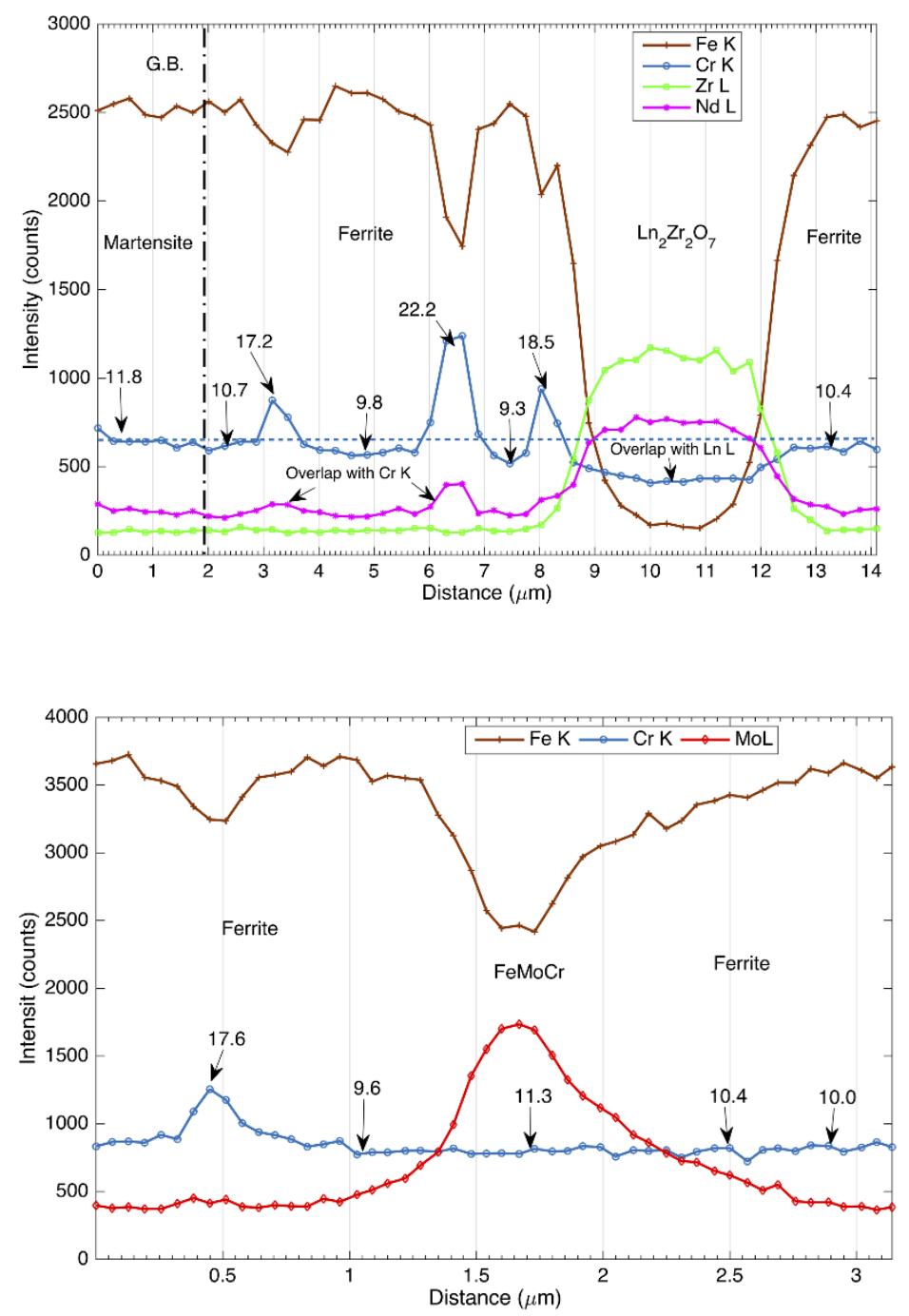

Figure 6. SEM images and EDS line scans of regions in the composite puck: (a)

martensite/ferrite grain boundary, $\mathrm{C} / \mathrm{N}$ precipitates, and zirconate inclusion in ferrite, and (b) $\mathrm{C} / \mathrm{N}$ precipitate and intermetallic in ferrite. 


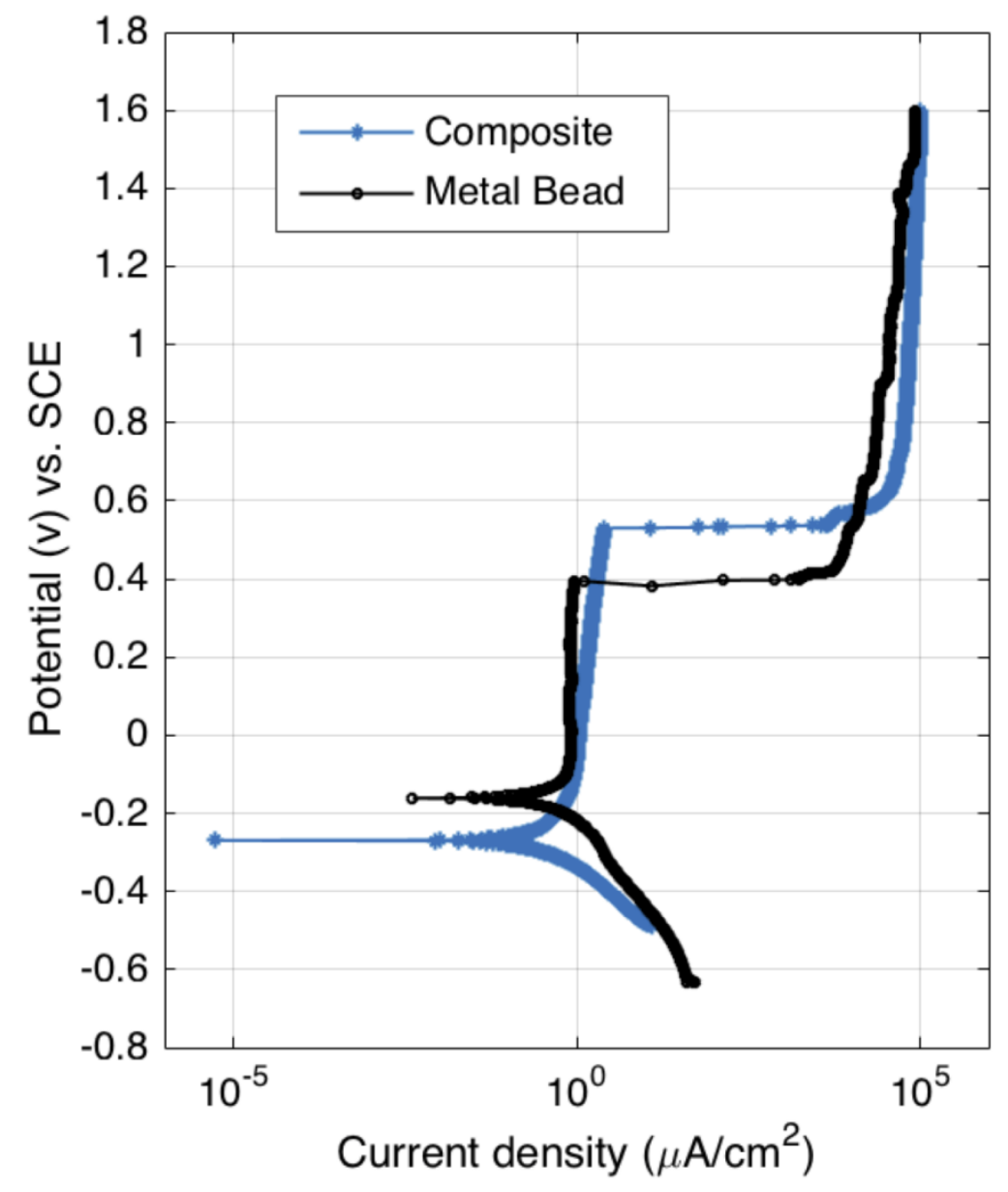

Figure 7. Potentiodynamic curves measured with the metal bead and composite electrodes. 

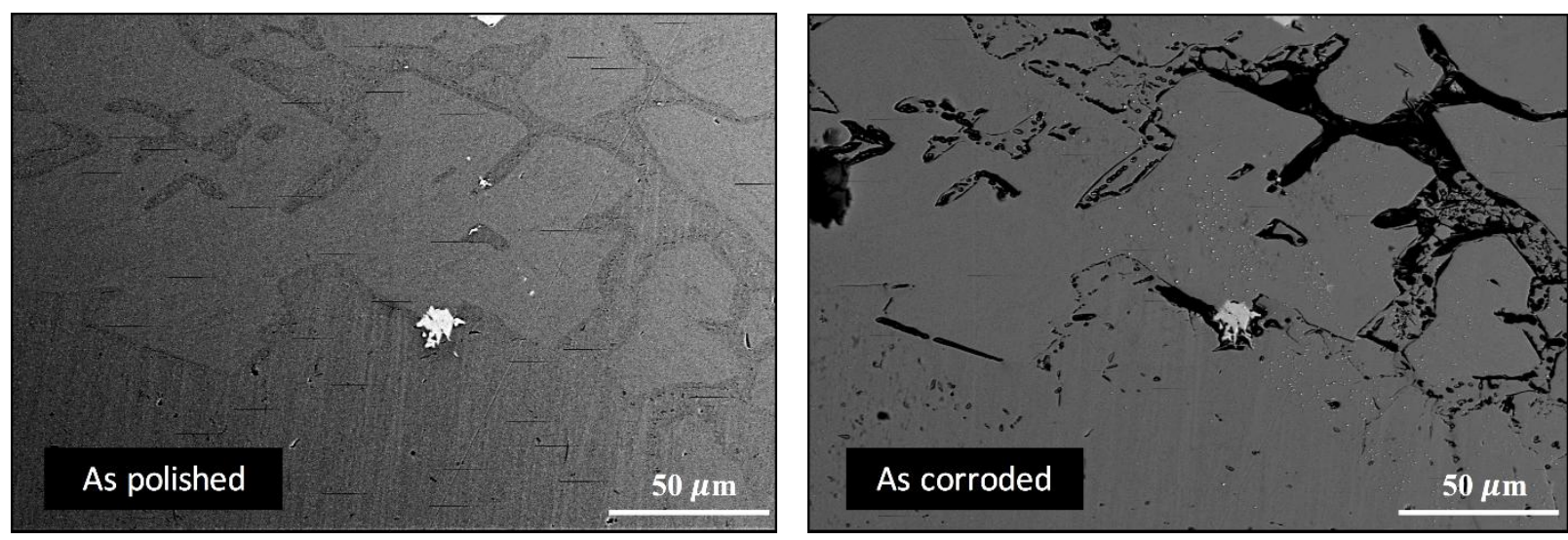

(a)
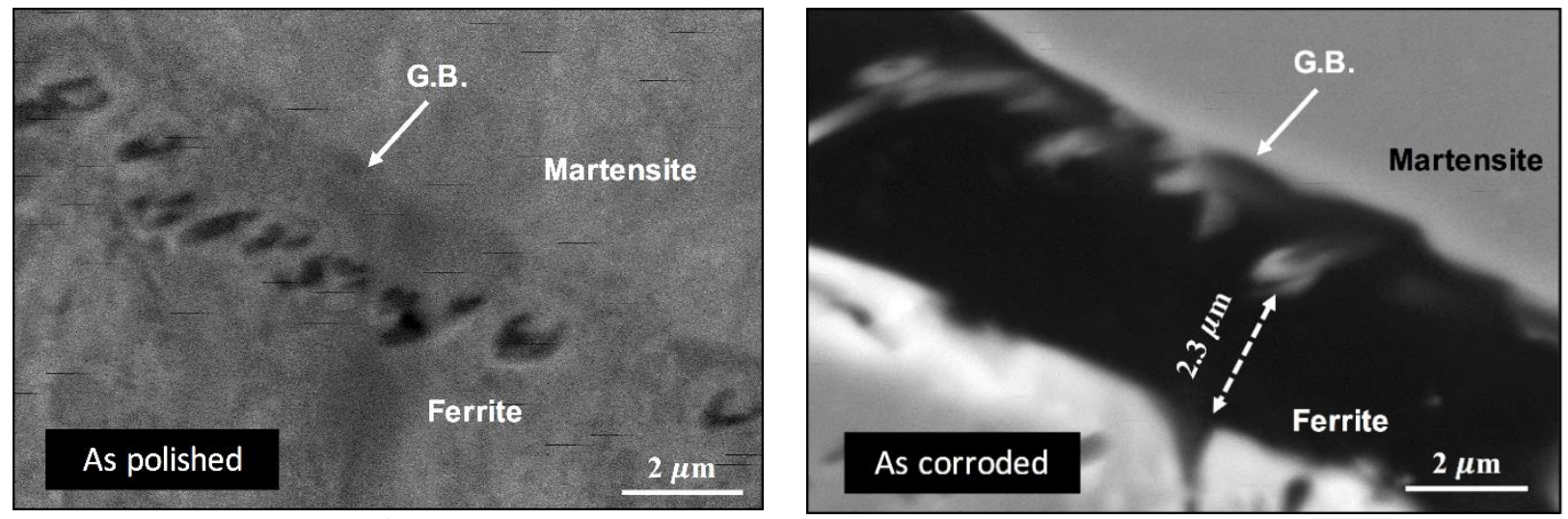

(b)

Figure 8. SEM (BSE) images before and after PD scan showing surface morphology change at (a) low and (b) high magnification. 


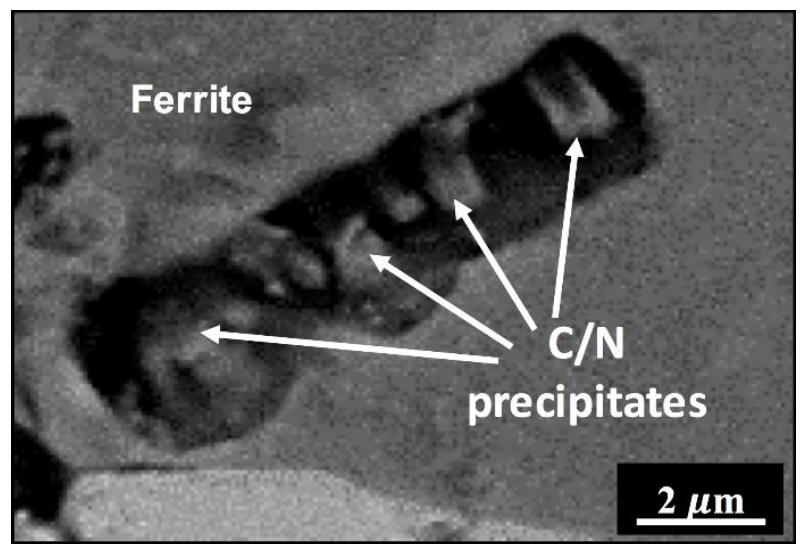

(a)

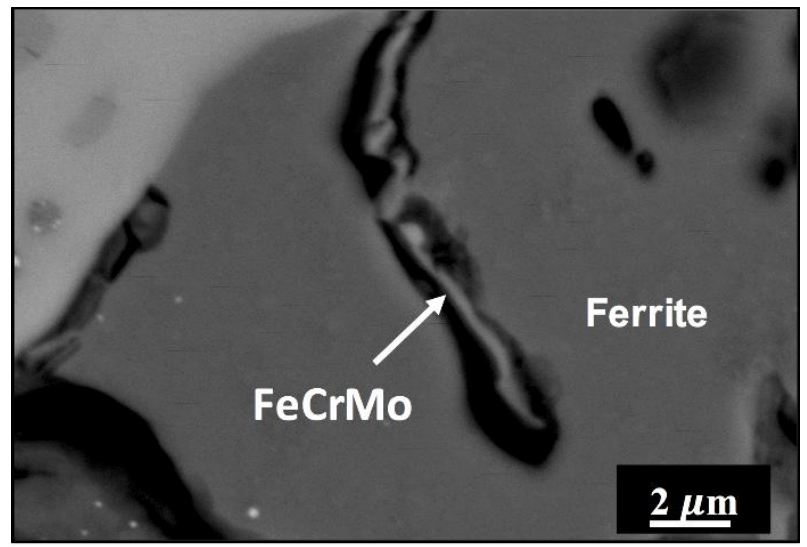

(c)

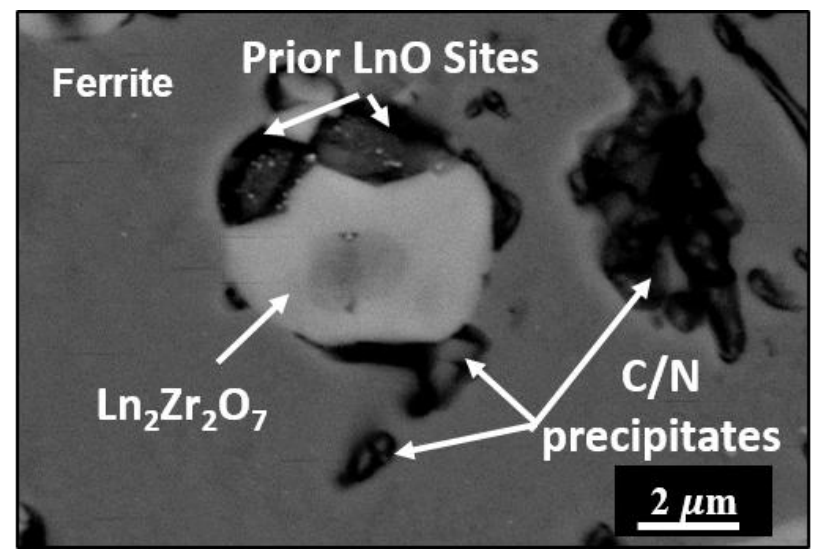

(b)

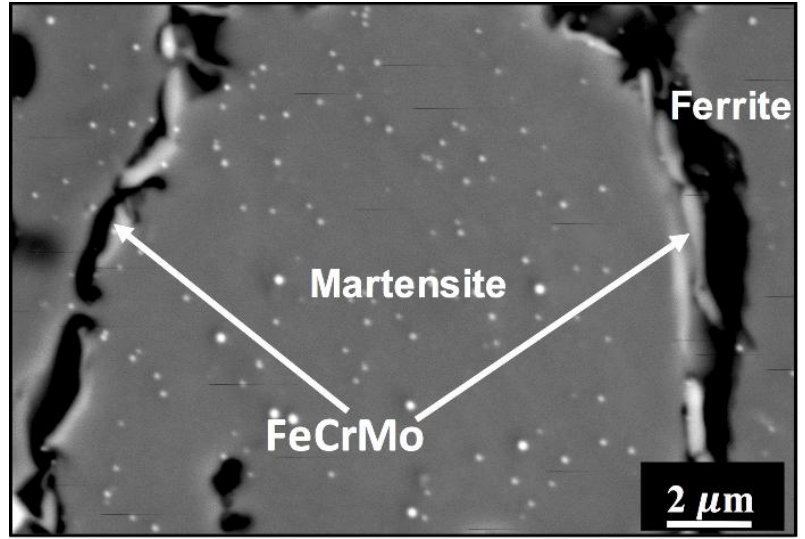

(d)

Figure 9 SEM images composite puck electrode after PD scan showing preferential corrosion of (a) and (b) ferrite surrounding $\mathrm{C} / \mathrm{N}$ precipitates, and (c) and (d) ferrite at intermetallic boundary. 

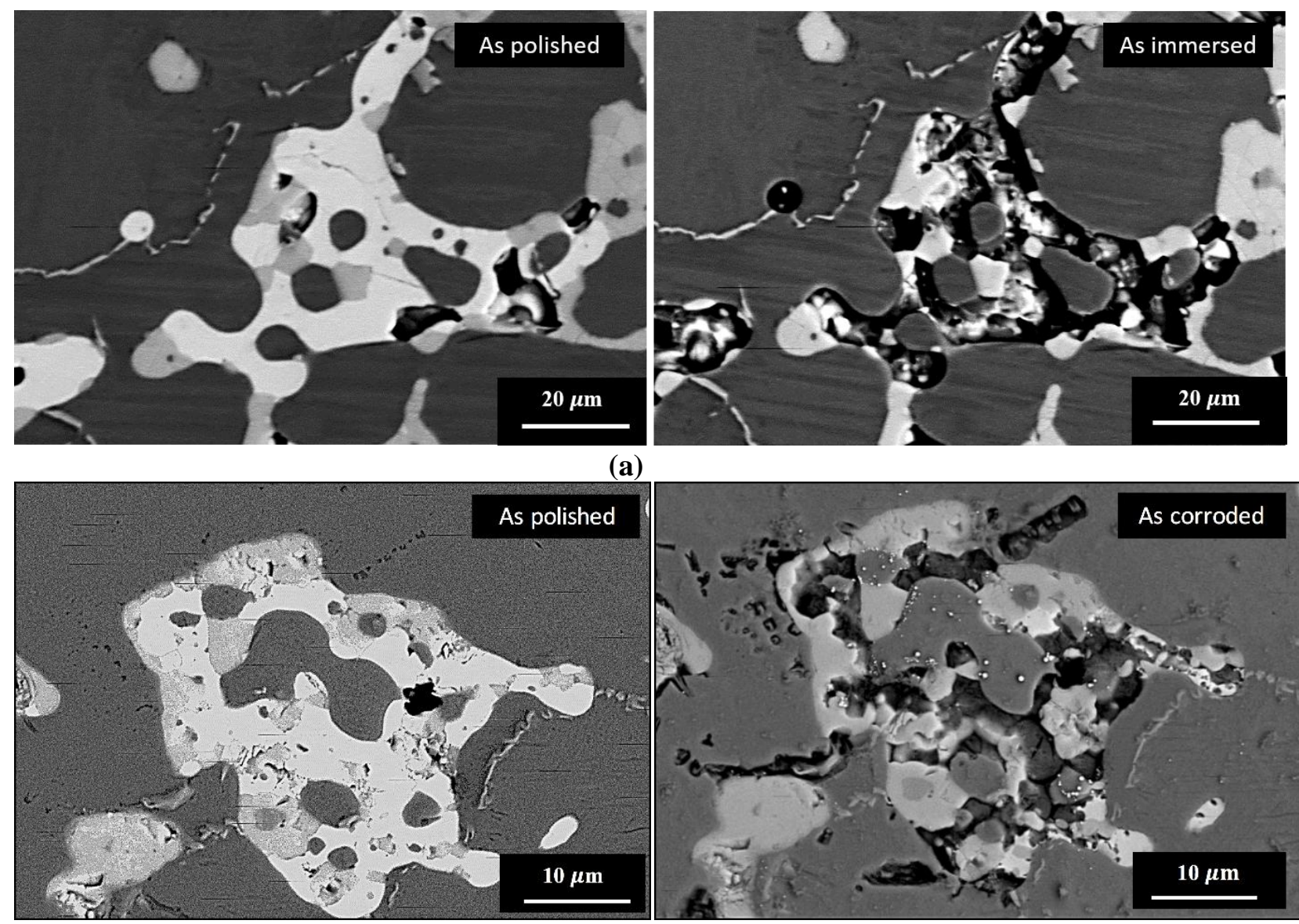

(b)

Figure 10. SEM images of ceramic puck electrode before and after (a) chemical dissolution and (b) PD scan. 

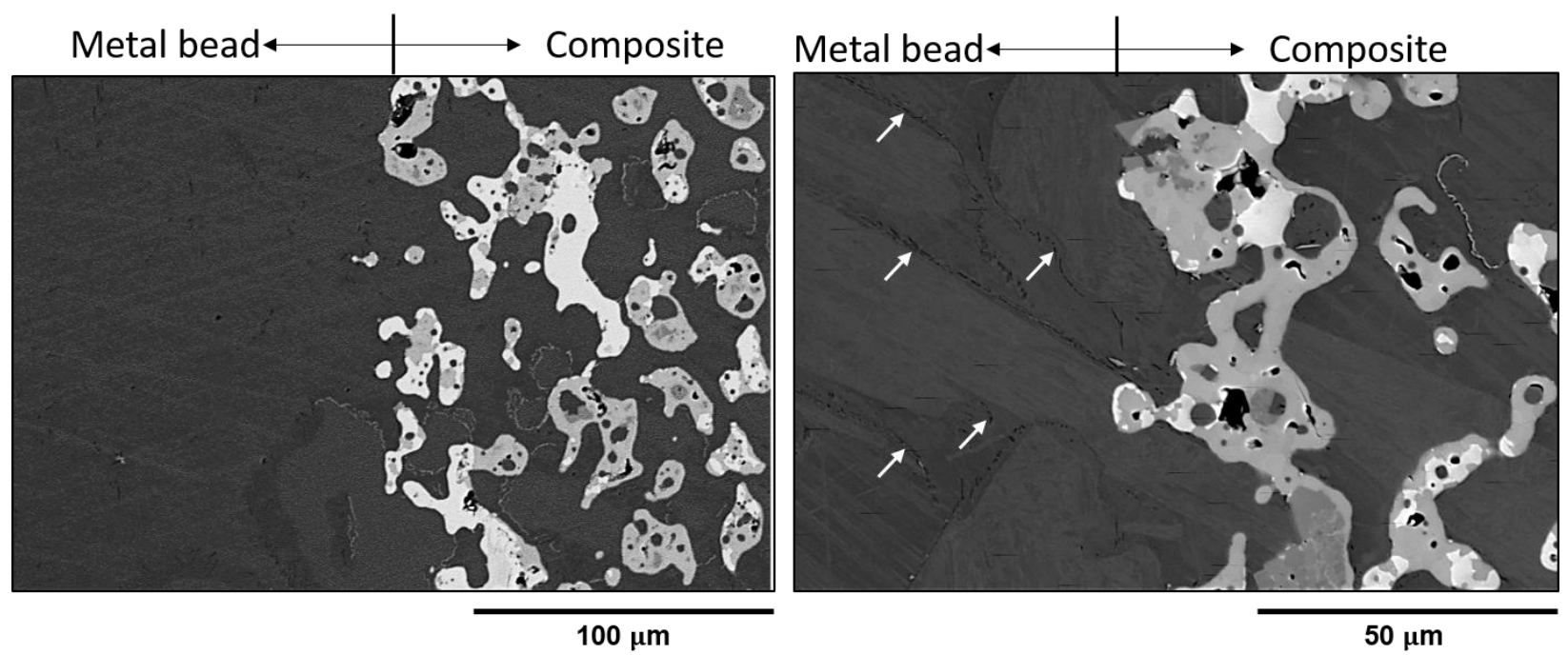

Figure 11. SEM image of interface electrode. The arrows in the right-hand image locate regions of $\mathrm{C} / \mathrm{N}$ precipitates formed at grain boundaries. 


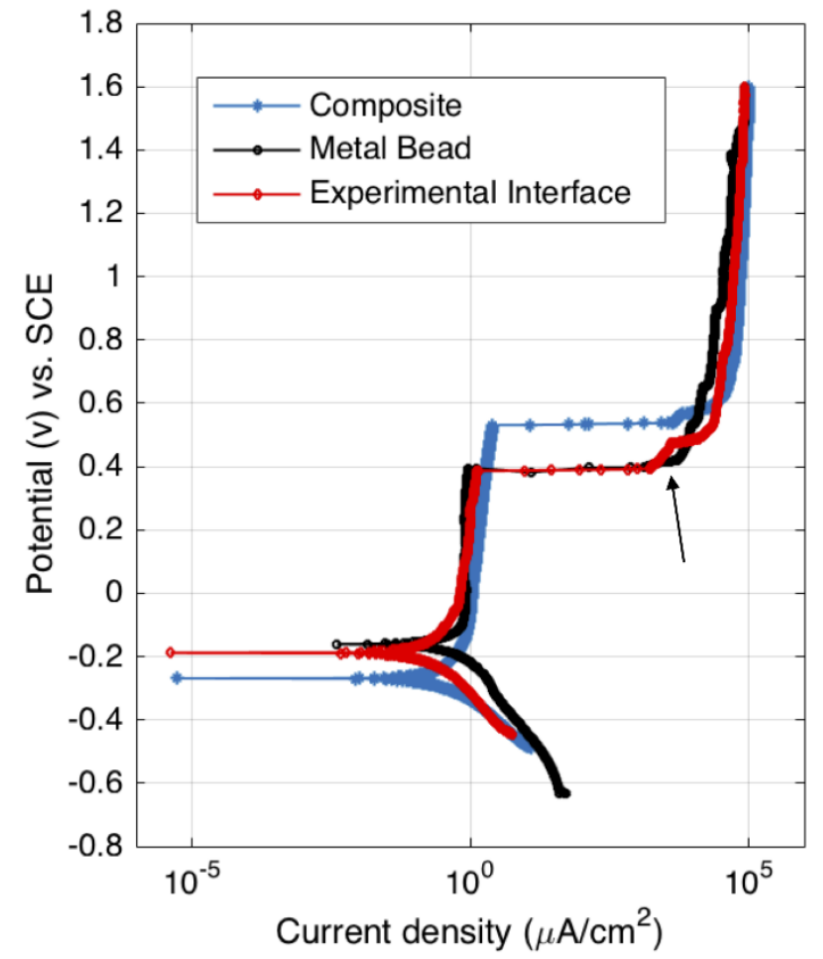

(a)

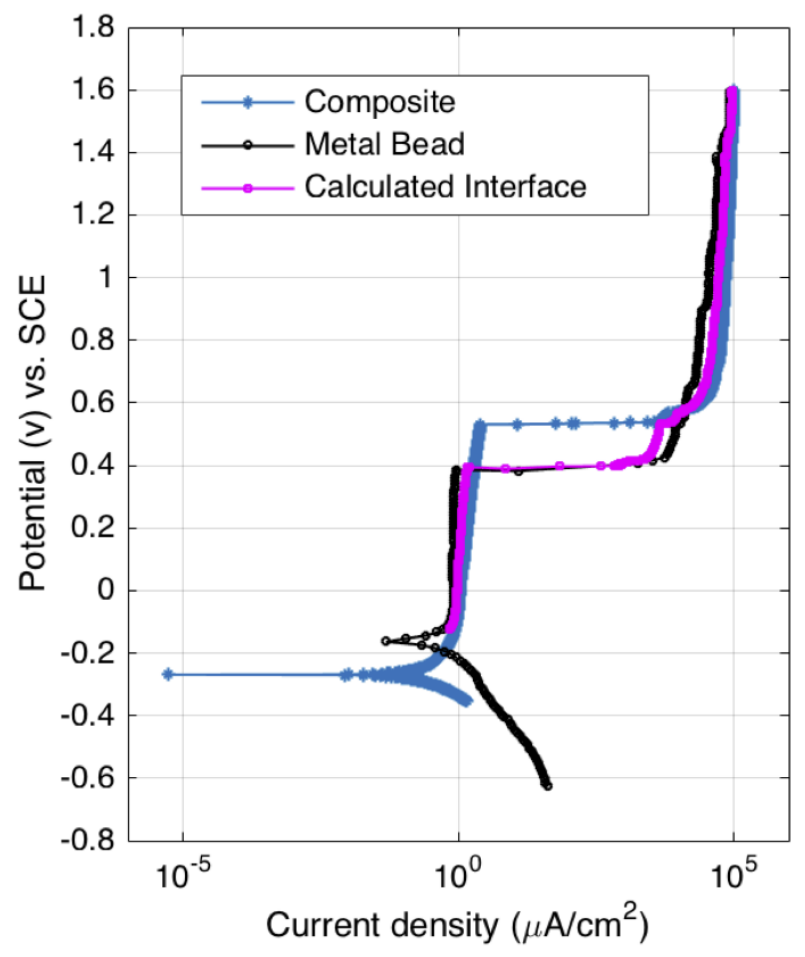

(b)

Figure 12. Measured PD curves of the metal and composite parts shown with (a) the measured PD curve of the interface electrode and (b) the calculated anodic curve of interface electrode.

The arrow locates a subtle difference between the responses of the metal and interface electrodes. 


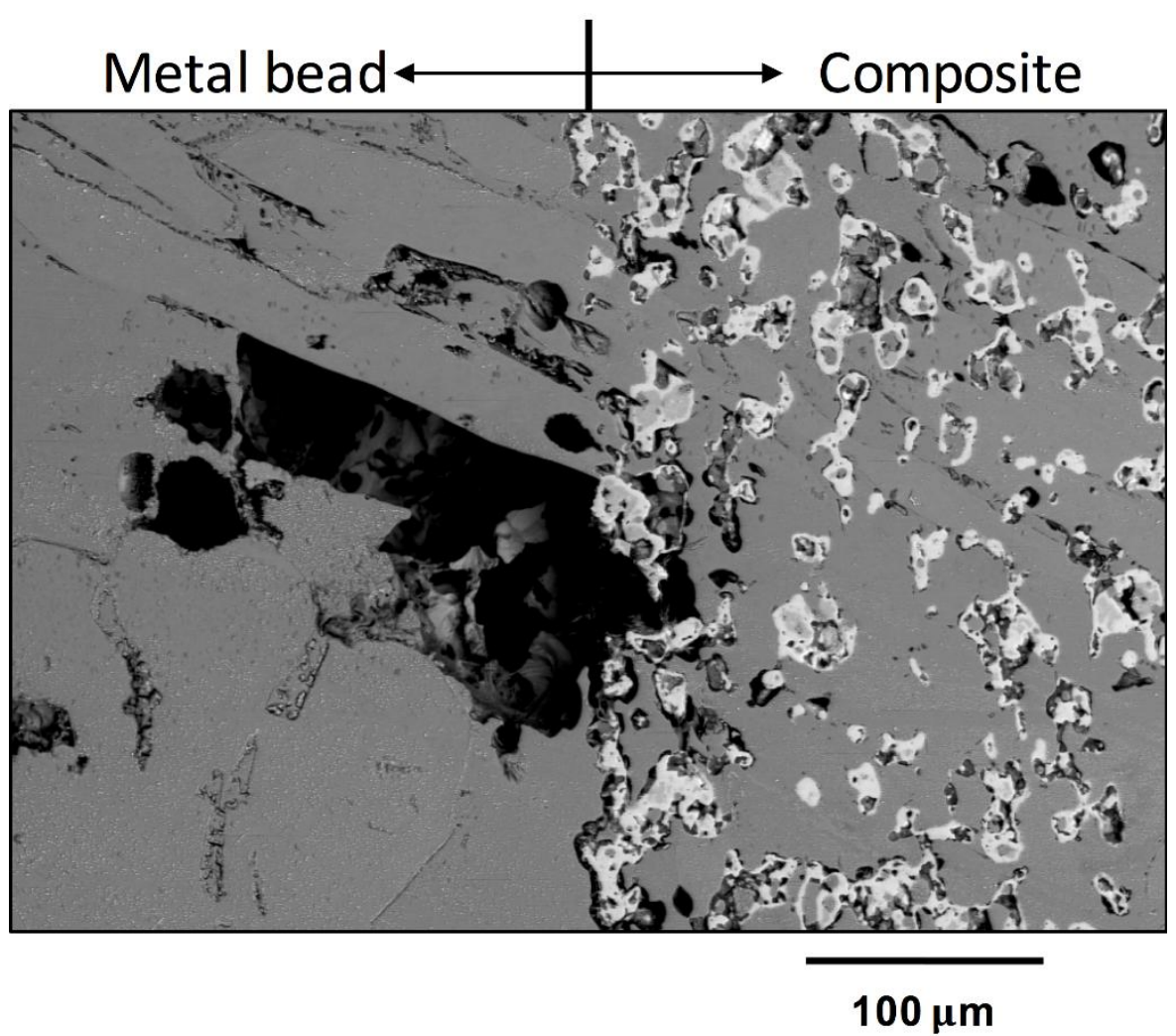

Figure 13. SEM image of the corroded interface electrode. 
Multiphase Alloy/Ceramic Composite Waste Form

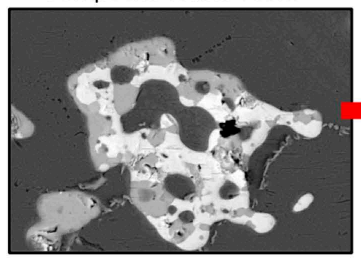

Martensite \& Ferrite matrix with

In zirconates $\mathrm{Cr}$-enriched FeMoCr and oxides $\mathrm{C} / \mathrm{N}$ precipitates intermetallics
Evaluate Electrochemical Identify Phase-Specific Corrosion Behavior

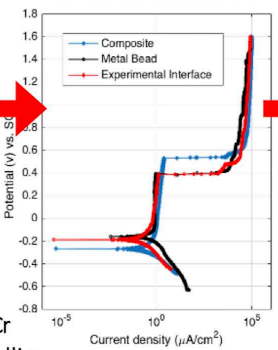

Current density $\left(\mu \mathrm{A} / \mathrm{cm}^{2}\right)$
Corrosion Processes

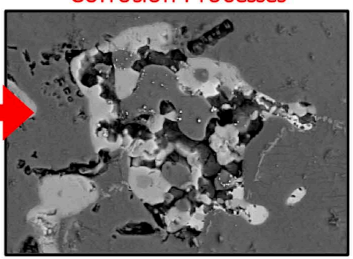

Sensitization corrosion

Galvanic corrosion

Chemical dissolution 